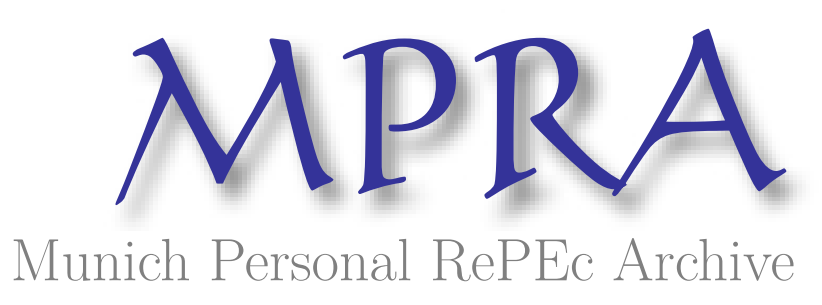

\title{
Fiscal decentralization, ideology, and the size of the public sector
}

Baskaran, T.

University of Heidelberg

2009

Online at https://mpra.ub.uni-muenchen.de/30188/

MPRA Paper No. 30188, posted 18 Apr 2011 11:45 UTC 


\title{
Fiscal decentralization, ideology, and the size of the public sector
}

\author{
Thushyanthan Baskaran ${ }^{a, *}$ \\ ${ }^{a}$ Department of Economics, University of Heidelberg, \\ Bergheimerstr. 58, 69115 Heidelberg, Germany
}

\begin{abstract}
No consensus has yet emerged on whether fiscal decentralization facilitates or impedes the growth of the public sector. One explanation for this ambiguity in the literature is that the effect of fiscal decentralization on public sector size depends on the government's ideology. This paper therefore develops a simple model to study theoretically how interactions between fiscal decentralization and the ideology of the government may influence the size of the public sector. Thereafter, the implications of the model are tested empirically with panel data from 18 OECD countries over the 1980-2000 period.
\end{abstract}

Keywords: Electoral competition, Fiscal decentralization, Public sector size JEL classification: H41, H71, H77

\section{Introduction}

Whether fiscal decentralization leads to a reduction or an increase in the size of the public sector is a well researched question within the field of fiscal federalism. The starting point of this literature is Brennan and Buchanan's famous conjecture which states that government intrusion into the economy will be smaller when the public sector is decentralized (Brennan and Buchanan, 1980). Several authors have attempted to test this Leviathan Hypothesis empirically, partly because Brennan and Buchanan explicitly invited researchers to do so $^{1}$, and partly because the validity of the hypothesis is based on a controversial view of government. Indeed, already Oates (1985) offers a number of arguments for the opposite relationship between decentralization and public sector size, for example that citizens' willingness to delegate responsibility to the government might increase when the public sector is decentralized.

Facing two competing theoretical predictions, Oates (1985) explores the relationship between decentralization and public sector size empirically. He runs two sets of cross-section regressions, first with data on US States and then with international data, using three measures of (de)centralization, and several different specifications. These regressions suggest neither a robust nor a significant relationship between fiscal decentralization and public sector size.

*Phone: +46-(0)31-786 1374, Fax: +46-(0)31-786 1326, Email: thushyanthan.baskaran@awi.uniheidelberg.de

1 "There are, then, clear empirical implications here that could be tested to determine the extent to which this explanation of revenue sharing and the structure of grants is an acceptable one" (Brennan and Buchanan, 1980, p.182) 
The overarching aim of the articles which build upon Oates' influential contribution is to explore the robustness of the finding of no significant relationship by using different data, an improved specification, considering alternative sets of countries, or other measures of decentralization.

For example, one issue that is ignored in Oates' study is whether the federal and subnational governments are able to limit the competitive pressures due to decentralization by colluding with each other. Grossman and West (1994) address this possibility in a study on the Canadian Provinces with time-series data. They indeed find that collusion between tiers of government increases the size of the public sector.

Another characteristic of Oates' study is that he conducts cross-section regressions at the US state level. In contrast, Marlow (1988) explores the link between decentralization and public sector size for the United States at the national level by using time-series data. He measures the aggregate size of the public sector with the ratio of total government expenditures to GNP, and regresses this variable on a measure of decentralization and two other controls. The results indicate, unlike in Oates' study, that decentralization in the US is negatively related to aggregate public sector size.

Other studies emphasize the importance of the underlying fiscal constitution for the effect of decentralization on public sector size. In these studies, it is argued that granting certain types of intergovernmental transfers to subnational governments will increase the size of the public sector when the federation is characterized by soft budget constraints and horizontal equalization schemes. For example, Grossman (1989) finds that while decentralization has indeed led to a smaller public sector in the US, intergovernmental grants have contributed to the growth of government. ${ }^{2}$ Jin and Zou (2002) obtain similar results in a panel data study on 32 industrial and developing countries. They find that expenditure decentralization leads to a larger aggregate government, whereas revenue decentralization seems to have the opposite effect. Vertical fiscal imbalances created by vertical transfers are found to expand the public sector. Overall, their results support the Leviathan Hypothesis for revenue but reject it for expenditure decentralization. Stein (1998) confirms these results for South American countries. He concludes that decentralization, when financed through central transfers, leads to an expansion of the public sector.

A related literature studies the impact of fiscal decentralization on public borrowing. However, this literature, too, is inconclusive. For example, while Neyapti (2010) finds that fiscal decentralization reduces deficits, De Mello (2000) reaches the opposite conclusion.

Compared to these studies, the scope of analysis is broadened in Rodden (2003). While his main concern continues to be the impact of the intergovernmental transfer scheme on the relationship between decentralization and size of the public sector, he also considers a number of political and institutional variables. He finds that fiscal decentralization tends to decrease the size of the public sector, but that public sectors grow faster when subnational expenditures are financed through intergovernmental grants. However, his key theoretical insight is that the overall impact of decentralization could be determined by how different tax bases are allocated to the various tiers of government. That is, fiscal decentralization might lead to a smaller public sector size particularly in such regimes where the fiscal constitution allocates those bases that are mobile to the subnational tier. This argument suggests the

\footnotetext{
${ }^{2}$ Corresponding to this, Schaltegger and Feld (2009) find for Switzerland that decentralization increases the probability of successful fiscal consolidations, while federal transfers reduce this probability.
} 
possibility that the suppliers of different production factors are locked in a battle to pass the financial burden of national and regional public goods onto each other by structuring the fiscal constitution appropriately.

Even though Rodden's argument is enlightening, it is made informally and its implications are not fully explored. Therefore, we attempt in this paper to elaborate on it by constructing a formal model that links the degree of mobility of factors of production to the fiscal preferences of their suppliers. In this model, we take the fiscal constitution (that is, the allocation of taxing powers over different tax bases between the tiers of government) as given, and endogenize tax rates and thus the size of the public sector.

While there are some contributions that analyze the political dimensions of of decentralization, e.g. Sengupta (2010) and Hindriks and Lockwood (2009), an explicit connection between ideology and decentralization and their joint impact on the size of government is rarely made in the literature. Sengupta (2010), for example, studies partisan effects in the allocation of federal transfers to subnational governments, while Hindriks and Lockwood (2009) analyze the impact of decentralization on electoral discipline.

We derive in the theoretical part of the paper that a decentralized public sector leads to a larger public sector size than a centralized one when the federal government is formed by a left-wing party, but that with a right-wing federal government, decentralization results in a smaller public sector size. In the empirical part of this paper, we test this hypothesis. We primarily use data from 18 OECD countries for this test, but also conduct a robustness check with a larger set of countries.

The remainder of this paper is organized as follows. In section 2.1, we describe the general framework of the model and introduce the notation, in sections 2.2 and 2.3 we derive the optimal size of the public sector with a benevolent government under centralized and decentralized regimes. These results will serve as our benchmark in evaluating the public sector size under "political" governments in section 3. Based on the theoretical results, we start our empirical investigation in section 4 . In section 4.1 we formulate our empirical hypothesis and describe the data. The results are presented in section 4.2. In section 5, we conclude.

\section{The basic model}

\subsection{General framework}

Assume a federation consisting of a continuum of jurisdictions whose measure is normalized to 1 . The population in each jurisdiction is also normalized to have a measure of 1 . Then, the number of inhabitants in the federation is unity.

In each jurisdiction, there are two types of inhabitants who are distinguished by the factor of production they supply to the production process. There are (i) "capitalists" who each supply inelastically 1 unit of capital and zero labor, and (ii) "laborers" who each supply inelastically 1 unit of labor and zero capital. We assume that capital is mobile between subnational jurisdictions, but that it cannot leave the country. This assumption can be justified by the empirical observation that capital is generally more mobile within than between nations. We also assume that inhabitants are immobile between jurisdictions, labor is therefore the immobile factor in the model.

In order to ensure consistency with later sections, we will in the following denominate the two groups of factor suppliers as right-wing (capitalists) and left-wing (laborers) inhabitants or, alternatively, voters. We refer to right-wing inhabitants with subscript $r$ and to left-wing inhabitants with subscript $l$. The share of right-wing inhabitants in jurisdiction $j$ is denoted 
with $a_{r}(j)$, and the share of left-wing inhabitants in $j$ with $a_{l}(j)=1-a_{r}(j)$. The share of right-wing inhabitants in the federation is given by $R=\int_{0}^{1} a_{r}(j) d j$ and the share of left-wing inhabitants by $L=\int_{0}^{1} a_{l}(j) d j$. Note that $0<R, L<1$ and $L=1-R$.

In each jurisdiction $j$, an industry produces an output good by using capital and labor according to the general production function $y(j)=F(k(j), l(j))$. Capital and labor demand by the industry in jurisdiction $j$ are denoted $k(j)$ and $l(j)$, respectively. We assume that the price of output is normalized to 1 . One implication of this assumption is that the price is not determined endogenously in the "home" market, and it is appropriate if output can be traded globally, in which case supply and demand are completely price-elastic. The objective of the industry is to maximize profits, taking the subnational and federal tax rates and available capital and labor supply as given.

There is a federal government that is responsible for the whole federation, and in each subnational jurisdiction a local government. It is assumed that the fiscal constitution allocates to the federal government the exclusive authority to tax returns on capital whereas subnational governments are allowed to exclusively tax wages which are paid within their jurisdiction.

The assumption that the federal tier taxes capital and the subnational tier taxes wages will drive our most important theoretical results. This means that if some capital were immobile and subnational governments were allowed to tax it while the federal government were allowed to tax labor, the results that we derive further below could be reversed. ${ }^{3}$ Naturally, to what extent this case is relevant is an empirical question. That capital is completely mobile is of course only an approximation of the fact that it is probably more mobile than labor. It is also a common assumption made in the literature on fiscal federalism (Zodrow and Mieszkowski, 1986). The assumption that the federal tier taxes exclusively the mobile and the local tier taxes exclusively the immobile factor is perhaps more controversial. Unfortunately, it is difficult to verify empirically to what extent this assumption is an accurate description of reality. The reason is that countries do generally not tax the production factors directly, but rather use highly complex tax systems consisting of a plethora of taxes (i. e. the income tax, the value added tax, sales taxes, etc.). While the overall burden from these various taxes will eventually be borne by the production factors, it is already difficult to derive the effective gross marginal and average tax rates on labor and capital accurately (McKee et al., 1986). What complicates this issue further in our context is the fact that countries vary in the allocation of tax instruments to the different tiers of government (Feld and Schneider, 2000), so that the extent to which the federal and subnational taxes are finally borne by labor and capital, respectively, will differ between countries. Unfortunately, we have not been able to find any empirical studies that calculate the shares of the total tax burden on the different factors of production for which the federal and subnational tier, respectively, are responsible.

For these reasons, it is difficult to "validate" empirically the assumption that only the federal government taxes capital and only subnational governments labor. However, given the lack of empirical evidence, assuming that the federal government taxes exclusively the mobile and local governments exclusively the immobile production factor is a reasonable "starting point" for a theoretical analysis of the interactions between decentralization and ideology since a rational constitutional assembly should allocate taxing powers between the tiers of government in this way.

\footnotetext{
${ }^{3}$ We are grateful to a referee for pointing this out.
} 
One advantage of assuming that taxing powers are allocated in an "economically efficient" way is that we can focus on the inefficiencies generated by the "political economy" of decentralization and abstract from inefficiencies due to vertical tax competition and tax sharing arrangements, which are already well understood (Keen and Kotsogiannis, 2002; Weingast et al., 1981). ${ }^{4}$ We show further below that there is indeed no difference between centralization and decentralization in terms of efficiency in our model if governments are welfare-maximizers.

The federal tax rate on capital is given by $t_{K}$ whereas the labor tax rate in jurisdiction $j$ is $t_{l}(j)$. Taxes are assumed to be per item. The federal government is constrained to be "uniform" in its tax rate whereas regional tax rates max vary. Given these assumptions, the gross return to capital is given by $r=\rho(j)+t_{K}$, where $\rho(j)$ denotes the net-of-taxes return to capital in jurisdiction $j$. Since we assume that capital is perfectly mobile throughout the federation, the net return of capital must be the same in all jurisdictions, that is $\rho(j)=\rho$.

The gross wage in jurisdiction $j$ is given by $w(j)=\omega(j)+t_{l}(j)$. In contrast to the net-oftaxes return to capital, the net-of-taxes wage rate $\omega(j)$ may vary between jurisdictions since labor is immobile. ${ }^{5}$

Capital and labor demand in jurisdiction $j$ are implicitly determined according to

$$
F_{k}(j)=\rho+t_{K} \text { and } F_{l}(j)=\omega(j)+t_{l}(j)
$$

where $F_{k}(j)$ and $F_{l}(j)$ denote the marginal product of capital and labor in jurisdiction $j$, respectively. Capital and labor demand in region $j$ are therefore a function of federal and regional taxes on capital and labor.

The gross return to capital is given by the following equilibrium condition ${ }^{6}$

$$
\int_{0}^{1} a_{r}(j) d j=\int_{0}^{1} k(j) d j
$$

That is, total capital supply in the federation must equal total capital demand in equilibrium. Note that since capital is mobile throughout the federation, the market for it is "national".

By totally differentiating equation 1 and using the assumption that capital is supplied inelastically, it is easy to show that the incidence of the federal tax is completely on capital ${ }^{7}$, i. e.

$$
\frac{d \rho}{d t_{K}}=-1
$$

\footnotetext{
${ }^{4}$ See Hindriks and Lockwood (2009) for a similar approach.

${ }^{5}$ Note that if we would assume a constant return to scale production technology, wages would also be the same in all jurisdictions. This is so because under constant returns, there is an optimal combination of labor and capital at all activity levels. Since capital is mobile, it will adjust such that the optimal combination of capital and labor is always achieved. Because the marginal product of labor is the same in all jurisdictions at this optimal combination irrespective of differing activity levels, equilibrium wages will also be the same.

${ }^{6}$ Each capitalist in the federation supplies one unit of capital, and there are $R=\int_{0}^{1} a_{r}(j) d j$ inhabitants. Thus, the gross supply of capital is also $R=\int_{0}^{1} a_{r}(j) d j$.

${ }^{7}$ It follows from equation 2 that $\int_{0}^{1}\left(d k(j) / d t_{K}\right) d j=0$. That is, since capital is supplied inelastically, demand in the individual jurisdictions must adjust such that it is equal to supply after a federal tax change. For the change in demand in region $j$ due to a change in the federal tax rate, it can be derived from equation 1 by totally differentiating: $d k(j) / d t_{K}=\left(\left(d \rho / d t_{K}\right)+1\right) /\left(d^{2} F / d k^{2}(j)\right)$. Combining this and the previous expression, we can see that the following must hold after a tax change $\int_{0}^{1}\left(\left(d \rho / d t_{K}\right)+1\right) /\left(d^{2} F / d k^{2}(j)\right) d j=0$. This expression can only hold if $d \rho / d t_{K}=-1$, i.e., when the tax incidence is completely on capital suppliers.
} 
Using the assumption that labor is supplied inelastically, the equilibrium condition for the labor market in jurisdiction $j$ is given by

$$
a_{l}(j)=l(j) .
$$

That is, labor supply in jurisdiction $j$ must equal demand in that jurisdiction. In contrast to capital, therefore, the market for labor is "local" because this factor is immobile.

Again, it is easy to show that the incidence of the regional tax on labor is completely on labor

$$
\frac{d \omega(j)}{d t_{l}(j)}=-1
$$

Given that taxes are always borne by the respective factor suppliers, an increase in the tax rate by one unit always decreases available income by one unit, i. e. there are no adjustments in the gross returns for capital and labor and the incidence of the taxes is completely on the factor suppliers (see the budget constraints for both factor suppliers further below).

On the consumption side of the economy, both right-wing and left-wing voters have identical preferences irrespective of the jurisdiction in which they live. These preferences are defined over private consumption, and two different public goods. There is a national public good $G$ which is provided by the federal government, and financed with federal revenues from taxes on capital. Second, each subnational government provides a local public good $g(j)$ which is financed with regional revenue from wage taxes.

We model the utility of inhabitants as quasilinear in private and public consumption. An inhabitant in jurisdiction $j$ has the following utility

$$
U_{i}(j)=c_{i}(j)+v(g(j))+W(G) \quad i=r, l .
$$

with $g(j)$ denoting the level of the local public good, $G$ the national public good and $c_{i}(j)$ private consumption by group $i=r, l$ in jurisdiction $j . v($.$) and W($.$) are the non-linear$ utility functions that represent individual preferences regarding the local and national public goods, respectively.

Inhabitants in each jurisdiction are distinguished by their budget constraints. That is, a right-wing inhabitant in $j$ has as budget constraint

$$
c_{r}(j)=\rho=\left(r-t_{K}\right),
$$

whereas a left-wing supporter has

$$
c_{l}(j)=\omega(j)=w(j)-t_{l}(j) .
$$

The budget constraint of the federal government is

$$
G=t_{K} \int_{0}^{1} a_{r}(j) d j,
$$

and that of regional government $j$ is

$$
g(j)=t_{l}(j) a_{l}(j)
$$




\subsection{Centralized public sector and benevolent governments}

As a benchmark, we derive the conditions that describe the level of public goods when the public sector is centralized and the government is a welfare-maximizer. Under centralization, the level of both the subnational and the national public goods is set by the federal government. We define social efficiency as a situation where the sum of the individual utilities is maximized. The objective function of the federal government is

$$
U^{s}=\int_{0}^{1} \sum_{i} a_{i}(j)\left(c_{i}(j)+v(g(j))+W(G)\right) d j, \quad i=r, l
$$

The budget constraint of the government at the federal tier and in each subnational jurisdiction $j$ is given by equation 9 and $10 .{ }^{8}$ Obviously, the national public good is a "pure" public good in the sense that every inhabitant in the country is able to consume it without reducing the consumption of other inhabitants, whereas the local public good $g(j)$ is local in the sense that it does not generate any spillovers in other jurisdictions.

By differentiating equation 11 with regard to $g(j)$ and $G$ and taking the various budget constraints into account, we obtain the following first order conditions for the optimal provision of the two public goods (see appendix A for the derivations)

$$
\begin{gathered}
1-\frac{d v}{d g(j)}=0, \text { and } \\
1-\frac{d W}{d G}=0 .
\end{gathered}
$$

These conditions determine the optimal levels of the regional and federal public goods. They state that in the social optimum, the marginal utility of a consumption of the local and national public goods must be equal to the respective marginal costs, which are 1 . We denote the solutions to these equations with $g^{*}(j)$ and $G^{*}$. For $g^{*}(j)$ to be viable, however, it must hold that the gross income of labor in jurisdiction $j$ is sufficient to pay the taxes associated with $g^{*}(j)$. It must therefore hold that

$$
a_{l}(j) w(j) \geq g^{*}(j) .
$$

We assume throughout this paper that this condition holds. ${ }^{9}$ Similarly, for $G^{*}$ to be viable, it must hold that

$$
r \int_{0}^{1} a_{k}(j) d j \geq G^{*}
$$

We assume throughout this paper that this condition, too, holds.

Note also that taxes are residually determined by the provision of the national and subnational public goods. In particular, whereas the capital tax is the same throughout the

\footnotetext{
${ }^{8}$ Obviously, we assume that each subnational jurisdiction has its own budget constraint even in centralized public sectors. It might be more realistic to assume for centralized regimes that the federal government treats the subnational sector as one homogeneous unit for taxation purposes, and then readjusts revenues between jurisdictions by means of horizontal transfers. However, when quasi-linear utility functions are used, the optimality conditions will not differ between both approaches because the federal government has no incentives to redistribute private consumption between the inhabitants of different jurisdictions.

${ }^{9} \mathrm{~A}$ corollary of this condition is that there is at least one laborer in every subnational jurisdiction.
} 
federation, the wage tax varies between jurisdictions. The tax burden on the laborers in jurisdiction $j$ is given by $t_{l}(j)=g(j) / a_{l}(j)$, and depends on the number of laborers living in the jurisdiction.

\subsection{Decentralized public sector and benevolent governments}

We now derive the equilibrium under a decentralized public sector. We understand decentralization as a situation where each tier of government maximizes the utility of its constituency independently. Due to the assumptions that (i) regional public goods do not generate any spillovers and (ii) that federal and subnational tax bases do not overlap, strategic interactions are irrelevant.

The objective function of a welfare-maximizing subnational government in jurisdiction $j$ is therefore

$$
U^{s}(j)=\sum_{i} a_{i}(j)\left(c_{i}(j)+v(g(j))+W(G)\right),
$$

where $c_{i}(j), i=r, l$ is given by equations 7 and 8 , and the budget constraint of the regional government by equation 10. The first order condition that pertains to the equilibrium level of the local public good is (see appendix A for the derivation)

$$
1-\frac{d v}{d g(j)}=0 .
$$

Thus, regional provision is determined according to a condition that is identical to equation 12, which implies that the first best level is provided by all jurisdictions. It is, however, not surprising that a decentralized public sector is generally efficient when governments are welfare maximizers because vertical and horizontal interactions are assumed to be non-existent.

Similarly, it can be shown that the level of national public good provided by the federal government is determined according to (see appendix A for the derivation)

$$
1-\frac{d W}{d G}=0 .
$$

Thus the same condition as in equation 13 is obtained, implying that the federal government provides the efficient level of the national public good.

Overall, we obtain that (i) if the allocation of taxing powers is such that the federal government may tax mobile and subnational governments immobile factors and (ii) federal and subnational governments are welfare-maximizers, then the first best equilibrium can be achieved under a decentralized public sector. This follows first from the fact that the burden of the regional wage tax is completely borne by labor suppliers, implying that regional labor demand is not reduced by wage taxes, and second because the federal capital tax is borne completely by capital suppliers, implying that capital demand in region $j$ is not reduced by an increase in the federation wide capital tax.

\section{The political economy of (de)centralization}

In the last section, we have assumed that the level of the public goods is determined by welfare-maximizing governments. This might be an unrealistic assumption, and is therefore abandoned is this section. Instead, we model the regional and federal governments as being 
elected by their respective electorates. The electorate of the federal government is the total population in the federation, the electorate of the regional government $j$ are all inhabitants of this jurisdiction.

Once elected, each party implements the "favored policy" of the voters it represents. A right-wing party is elected into office in jurisdiction $j$ when $a_{r}(j) \geq 1 / 2$. Otherwise, the leftwing party is elected into office. Similarly, a right-wing party controls the federal executive if $R=\int_{0}^{1} a_{r}(j) d j \geq 1 / 2$. Since $L=1-R=\int_{0}^{1} a_{l}(j) d j$, a left-wing party controls the federal executive when $L>1 / 2$. Note that we assume that the right-wing party wins the election in both the subnational jurisdictions and at the federal level in cases where the share of right-wing voters is exactly $50 \%$ (and therefore equal to the share of left-wing voters). ${ }^{10}$

By "favored policy", we mean that each party implements the level of the regional and federal public goods preferred by its voters. Qualitatively, this assumption implies that if a jurisdiction $j$ is ruled by a right-wing government, the level of the regional public good will be set as high as possible because the associated tax burden is completely borne by leftwing voters (labor suppliers). On the other hand, if the federal government is controlled by the right, it will provide a sub-optimally low level of the national public good because its constituency has to bear the full costs of provision but disregards the benefits that accrue to left-wing voters.

Conversely, if the left controls the government in jurisdiction $j$, it will set the level of the regional public good too low because it ignores the benefits that accrue to the right-wing supporters living in that jurisdiction. On the other hand, if the federal executive is in the hands of a left-wing party, the national public good will be over-provided. ${ }^{11}$

We will assume in the following that there is some upper limit to the level of public goods, for example because of a constitutional provision which has been established to prevent expropriatory taxation or because public expenditures which generate only small social benefits might become politically unfeasible from a certain point onward. ${ }^{12}$

\footnotetext{
${ }^{10}$ This assumption is only made for convenience but does not qualitatively affect any of the results because the population share function $a_{l}(j)=1-a_{r}(j)$ is continuous.

${ }^{11}$ The explanation that the constitutional assembly establishes a socially optimal fiscal constitution may seen contradictory to the assumption that political governments are only interested in the welfare of their constituencies and attempt to "exploit" the other constituency as much as possible. One (in our view reasonable) response to such objections is that constitutions usually have to be approved by a qualified majority, while governments are elected by $50 \%$ (or less) of the electorate. Since a larger majority has to be attained before a constitution is established, it is more difficult to codify the preferential treatment of one of the two constituencies in the constitution. Rather, the necessity to obtain a qualified majority should ensure that the constitution is indeed socially optimal. There are no such considerations to obtain qualified majorities in the post-constitutional stage, and - except for constitutional limitations - governments are free to exploit certain groups once they are elected by a simple majority.

${ }^{12}$ It might seem unreasonable that one seeks to prevent exploitation of one particular group through an upper limit on the level of public goods rather than through a limit on tax rates. However, expenditures and taxes are clearly related, and formulating the constitutional restrictions in this way facilitates the derivation of quantitative results. Assuming tax instead of spending limits would make the spending undertaken in a subnational jurisdiction that is controlled by a right-wing party dependent on the wage rate and the number of labor suppliers in that jurisdiction. Thus, without assuming that the production technology exhibits constant returns to scale (and therefore leads to the same wage rate in all jurisdictions), it would be impossible to derive explicit expressions for the size of the public sector. Apart from this technical argument, the assumption can be further rationalized by the fact that over-provision of a public good is a particularly visible sign of government inefficiency. This is especially true in rich societies (i. e. as the OECD countries which we primarily use further
} 
To obtain quantitative results, we will consecutively impose more structure on the problem. We start by assuming that the utility functions in equation 11 are given by the customary logarithmic function, i. e. $v=\ln (g)$ and $W=\ln (G)$. Then, we obtain for the optimal level of each regional public good $g^{*}(j)=1$, and for the national public good $G^{*}=1$. The optimal public sector size is given by $S^{*}=\int_{0}^{1} g^{*}(j) d j+G^{*}=2 .{ }^{13}$

Because we assume that governments only consider the utility of their voters, a left-wing government in jurisdiction $j$ strives to maximize

$$
U_{l}(j)=a_{l}(j)\left(c_{l}(j)+\ln (g(j))+\ln (G)\right),
$$

i. e. the sum of the utilities of all its voters. Thus, the level of the local public good is determined by the following condition (see appendix A for the derivation)

$$
\frac{1}{a_{l}(j)}-\frac{1}{g(j)}=0 \text {. }
$$

This equation can be solved to $g_{l}(j)=a_{l}(j) \leq 1$ for the level of the regional public good under a left-wing subnational government.

On the other hand, if the right controls the local government it will set the level of the regional public good as high as possible. We assume that the highest possible level of the regional public good $g_{r}(j)$ is the socially efficient level $g^{*}(j)$, that is $g_{r}(j)=g^{*}(j)=1$.

We make this restrictive assumption to avoid that the following argument is complicated by technical details. We show in appendix B that the main results continue to hold in more general cases. Note, however, that the imposition of this particular spending limit can be justified on grounds of plausibility. While left-wing supporters have to pay more taxes than they would like to when the maximum possible public good level is equal to the efficient level, right-wing local governments can "justify" the tax burden from a "moral" perspective on the grounds that it maximizes aggregate welfare.

At the federal level, the amount of the national public good provided by an executive controlled by the right is determined by maximizing

$$
U_{r}=\int_{0}^{1} a_{r}(j)\left(c_{r}(j)+\ln (g(j))+\ln (G)\right) d j,
$$

which is the sum of the utilities of all right-wing voters in the federation.

The first order condition is (see appendix A for the derivations)

$$
\frac{1}{R}-\frac{1}{G}=0,
$$

below to test the theory) where marginal increases in tax rates result in high amounts of revenue, thus causing expenditures to be a more obvious signal for government inefficiency than the associated tax rates.

${ }^{13}$ Note that not only the volume but also the distribution of spending between the two tiers of government is relevant for efficiency. For example, an equilibrium where the federal government would spend $G=2$ and subnational governments $g(j)=0$ is not optimal even though the aggregate public sector size is equal to the efficient public sector size. 
with $R=\int_{0}^{1} a_{k}(j) d j$ denoting the total number of right-wing voters in the federation. Solving this equation, we obtain for the level of the federal public good when the right is in control of the federal government $G_{r}=R<1=G^{*}$.

When the left controls the federal government, it will strive to provide the highest possible level of the federal public good. We again impose that the maximum level cannot be higher than the socially optimal level, that is $G_{l}=G^{*}=1$ (a more general case is analyzed in appendix B).

In the following subsections, we analyze the size of the public sector under various policy regimes and administrations. We start by discussing the case of a centralized executive, and then move on to discuss the impact of decentralization. The aim of these subsections is to derive empirical predictions which simultaneously address the institutional regime of a country (centralization vs. decentralization), and the prevailing political environment (that is, which of the two groups has the majority in both the subnational jurisdictions and the federation as a whole). In the empirical part of the paper, we will test these predictions.

\subsection{Public sector size under centralization}

We first derive the size of the public sector under a centralized regime. Under centralization, the federal government chooses both the level of the national and that of each subnational public good. Thus, we need to discuss two separate cases: the case where the left has a majority in the whole federation, and the case where the federal government is controlled by the right. Keeping in mind that the number of right-wing voters is given by $R=\int_{0}^{1} a_{r}(j) d j$, the federal executive is controlled by the right when $R \geq 1 / 2$. Under the assumption that the utility function $W($.$) is logarithmic, the public sector size of the federal tier is then given$ in equilibrium by $R .{ }^{14}$ The aggregate size of the public sector at the subnational tier is given by $\int_{0}^{1} 1 d j=1$ because the highest possible level of the local public good will be chosen in all jurisdictions (which is 1). Thus the aggregate size of the public sector when the right is in control and the country is centralized is given by

$$
S_{r}^{c}=1+R<2 .
$$

On the other hand, when $L>1 / 2$, the left-wing party controls the government. It will choose the maximum level of the national public good, and in each jurisdiction the level of the subnational public good that is preferred by its constituency. The size of the public sector is given in this case by

$$
S_{l}^{c}=1+\int_{0}^{1} a_{l}(j) d j=1+L<2 .
$$

We can reach two conclusions from these expressions. First, the political equilibrium leads to a smaller than efficient aggregate public sector size, both when the federal government is controlled by the right and when it is controlled by the left. Second, there is no systematic difference in the aggregate size of the public sector chosen by the two parties. However, there are differences in the distribution of spending between tiers of government. If the left is in the majority, the aggregate size of the public sector at the subnational tier will be lower than in the first-best equilibrium. We obtain the opposite results when the right has the majority.

\footnotetext{
${ }^{14}$ We use equation 22 to obtain this result.
} 


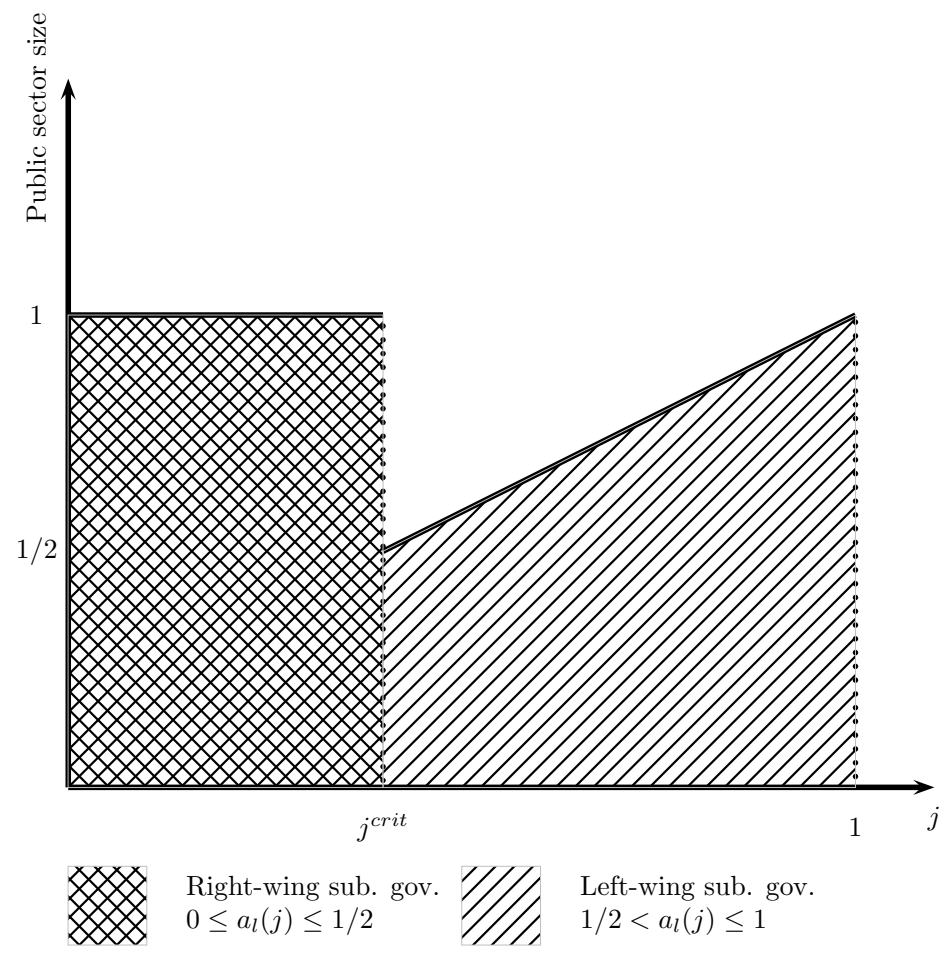

Figure 1: Subnational public sector size under a decentralized public sector

\subsection{Public sector size under decentralization}

When the public sector is decentralized, the situation is different. The federal government continues to be controlled by the party which has the federation-wide majority. The determination of the number of jurisdictions controlled by the left- and the right-wing parties is more complicated than in the case of centralization, however. This number depends on both the relative shares of the two groups in the federation, and their spatial distribution between jurisdictions. On the most basic level, the two groups could be "equally" or "unequally" distributed. If both groups are equally distributed, each jurisdiction is populated by $a_{r}(j)=R$ right-wing and $a_{l}(j)=L$ left-wing voters. Thus if the right has the federation-wide majority $(R \geq 1 / 2)$, it will not only control the federal executive but also all subnational governments and vice versa. Obviously, when the two groups are equally distributed, the number of jurisdictions controlled by either group and in turn the size of the public sector is the same as under centralization. This case therefore does not need further analysis.

The more interesting case is the one where right- and left-wing voters are unequally distributed between jurisdictions, and it is here where decentralization makes a critical difference. Assume without loss of generality that jurisdictions are ranked in descending order according to the number of right-wing supporters, and that the function $a_{r}(j)=1-a_{l}(j)$ is continuous. That is, $j=0$ is the jurisdiction with the highest share of right-wing supporters and $j=1$ the jurisdiction with the smallest share. Denote with $j^{\text {crit }}\left(0 \leq j^{\text {crit }} \leq 1\right)$ the critical jurisdiction where the share of right wing supporters is exactly $50 \%$. Then, all subnational jurisdictions 
$j \leq j^{\text {crit }}$ are controlled by right-wing administrations and all jurisdictions with $j>j^{\text {crit }}$ are controlled by left-wing administrations. ${ }^{15}$

The aggregate public sector size at the subnational tier is given by

$$
S^{s u b}=\int_{0}^{j^{c r i t}} 1 d j+\int_{j^{c r i t}}^{1} a_{l}(j) d j
$$

using the fact that $a_{l}(j)=\left(1-a_{r}(j)\right)$, this expression simplifies to

$$
S^{s u b}=1-\int_{j^{c r i t}}^{1} a_{r}(j) d j .
$$

This formula can be explained with the help of figure 1. In this figure, all subnational jurisdictions with $j \leq j^{\text {crit }}$ are controlled by right-wing administrations. They will thus chose the highest possible level of the local public good, which is 1 . The jurisdictions $j>j^{\text {crit }}$ will be controlled by left-wing administrations. In these jurisdictions, the government will choose the level of the public good preferred by the left-wing voters, which equals the share of left-wing voters in the jurisdiction. Since we have assumed that jurisdictions are ranked according to the share of right-wing voters, the size of the public sector is equal to $1 / 2$ in the jurisdiction next to the critical jurisdiction, which is the first controlled by the left, and increases thereafter monotonically.

Having derived the aggregate size of the public sector at the subnational tier, the total public sector size can be easily expressed as follows. If the federal government is controlled by the right, the aggregate size of the public sector under decentralization $\left(S_{r}^{d}\right)$ is given by

$$
S_{r}^{d}=R+1-\int_{j^{c r i t}}^{1} a_{r}(j) d j
$$

because a right-wing federal government chooses $G_{r}=R$ for the national public good.

Since left-wing administrations will provide the highest possible and thus the socially efficient amount of the national public good, the aggregate public sector size under a left-wing federal administration and a decentralized public sector $\left(S_{l}^{d}\right)$ is given by the following expression:

$$
S_{l}^{d}=2-\int_{j \text { crit }}^{1} a_{r}(j) d j .
$$

By considering these expressions, we can compare the size of the public sector under different regimes and governments. We derive the following result from the model.

Result A: Since $\int_{j \text { crit }}^{1} a_{r}(j)<R=(1-L)<1$, the relationship

$$
S_{l}^{d}>S_{l}^{c} \text { and } S_{r}^{d}<S_{r}^{c},
$$

holds.

\footnotetext{
${ }^{15}$ If there is no jurisdiction for which $a_{r}(j)=a_{l}(j)=0.5$, then all subnational governments must be formed by right-wing or left-wing parties, depending on whether $R>L$ or vice versa. In this case, the critical jurisdiction can be defined as $j=0$ when $R<L$ or $j=1$ when $R>L$.
} 
That is, decentralized public sectors exhibit bigger governments than centralized regimes when the federal administration is left-wing. Conversely, decentralized public sectors exhibit smaller governments than centralized regimes when the federal government is right-wing.

\section{Empirical evidence}

\subsection{Hypotheses, empirical model and data}

The theoretical Result $A$ suggests the following empirical hypothesis.

Hypothesis A: Fiscal decentralization leads to a larger aggregate public sector size than centralization when a left wing party controls the federal government, and to a smaller aggregate public sector size than centralization when a right-wing party controls the federal government

One problem that emerges when one attempts to test this hypothesis empirically is that "real-world" countries almost never match the assumptions upon which the theoretical model is built. We have, for example, treated centralization as a regime in which subnational governments have absolutely no role to play. This assumption is inappropriate given that even the most centralized states allow for some amount of local self-rule. Second, we have continuously talked about "federal" and "subnational" governments, thus evoking the impression that only federations can be decentralized. In reality, this is not the case. Whether a country is decentralized or not is primarily determined by the prevailing political reality and not by whether the constitution designates the country as a federation or a unitary state. ${ }^{16}$ Third, we have assumed that there are only two parties in the country, and that each individual is associated with one of these two parties, and furthermore that this association depends only on the supplied factor of production. We therefore have to provide a reasonable "translation" of the concepts used in the theoretical part in order to specify a meaningful empirical model.

In this empirical section, we treat decentralization as a continuous concept which is based on the amount of fiscal autonomy of subnational governments. We take a dual approach in measuring fiscal decentralization. There are two types of fiscal decentralization, one that is related to the expenditure and one that is related to the revenue side of the budget, and both might exhibit different effects on the size of the public sector in real-world countries (even though there should be no difference theoretically since taxes and spending are simultaneously determined in our model).

Expenditure decentralization (Exp. dec.) is defined in this paper as the share of subnational expenditures to total government expenditures. Revenue decentralization (Rev. dec.) is accordingly defined as the share of subnational revenues to total government revenues. Panel data on the level of expenditure and revenue decentralization for a large number of countries is readily available from the "Country Database on Fiscal Decentralization" constructed by the World Bank. ${ }^{17}$ This database uses original expenditure and revenue data from the IMF's GFS database to calculate the decentralization indicators.

Even though the decentralization data are available for a fairly large set of countries, we focus, for two reasons, on OECD countries. First, all countries in this group have a similar

\footnotetext{
${ }^{16}$ Indeed, some federal countries are far less fiscally decentralized than unitary states, see Stegarescu (2005) for empirical evidence to this effect.

${ }^{17}$ This data can be downloaded under: www1. worldbank. org/publicsector/decentralization/WBFDICountryDatabase Jan2005. xls.
} 
institutional and economic structure, so that we can be reasonably sure that the variables of interest have similar effects and interpretations. For example, it is not clear ex ante whether a process of decentralization in a democratic state will have the same characteristics and consequences as in an autocracy. Second, there is also the issue of data quality once non-OECD countries are considered. In particular, measures for government ideology are more reliable and detailed for OECD than non-OECD countries. However, we also conduct robustness checks with a larger set of countries in section 4.2.3.

Initial investigations of Hypothesis $A$ are conducted in figure 2 and 3 for a sample of 18 high-income OECD countries ${ }^{18}$ over the 1980-2000 period. These figures are based on the observations that are included in the baseline regressions reported further below.

Public sector size is measured in these figures by total government expenditures divided by GDP. The data is obtained from the OECD's Economic Outlook database.

The ideological position of the central government is measured by an index from the CPDS I database provided by Armingeon et al. (2008). ${ }^{19}$ This index, denominated Ideology, assumes the value 1 when the government is considered to be far-right and 5 when it is considered to be far to the left (see table 1). The use of this disaggregated measure also enables us to consider coalition governments and intermediate regimes since the clear distinction of governments into left and right put forward in the theoretical section is seldom observed in reality. One drawback of this measure is, as noted further above, that it is only available for 23 high-income OECD countries.

Even though the CPDS I ideology data is available for 23 countries, three of them had to be dropped from the database because of the unavailability or excessive number of missing observations for the decentralization data from the World Bank database. (That is, data for Japan and New Zealand is unavailable over the whole sample period, and data for Greece is only available in 1980 and 1981.) Furthermore, Iceland and Luxembourg were dropped because decentralization does not seem to be a reasonable concept for such small countries.

In both figures, we split the observations according to whether the central government in a given country-year combination is left-wing (Ideology $>3$ ) or right-wing $($ Ideology $<3) .{ }^{20} \mathrm{We}$ then fit linearly the data on public sector size and expenditure decentralization for these two subgroups in figure 2. In figure 3, we plot the data for revenue decentralization.

Both figures seem to confirm our conjecture on the relationship between decentralization and size of the public sector. For the subgroup of observations with left-wing administrations, we observe a positive relationship between both expenditure and revenue decentralization and public sector size. For the subgroup with right-wing administration, the relationship is negative. However, these simple figures do not control for other confounding factors and can therefore only provide preliminary evidence.

\footnotetext{
${ }^{18}$ Which are: Australia, Austria, Belgium, Canada, Denmark, Finland, France, Germany, Ireland, Italy, Netherlands, Norway, Portugal, Spain, Sweden, Switzerland, United Kingdom, United States.

${ }^{19}$ The original source is the Political Data Yearbook (various issues) published by the European Journal of Political Research.

${ }^{20}$ Note that we drop observations for which Ideology $=3$ ("centrist" governments).
} 


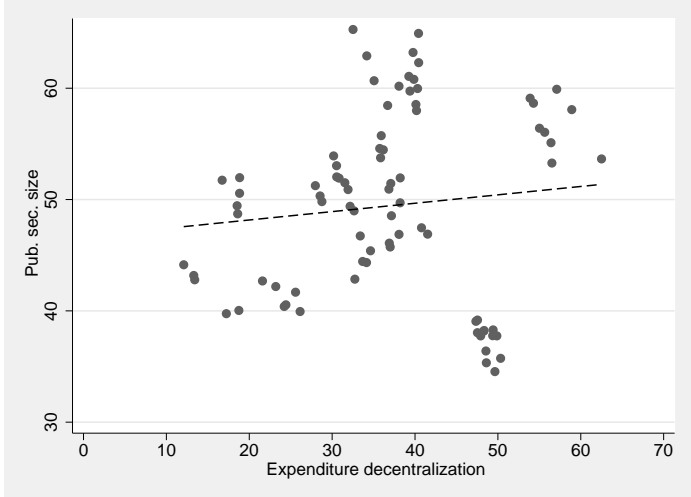

(a) Left-wing administrations

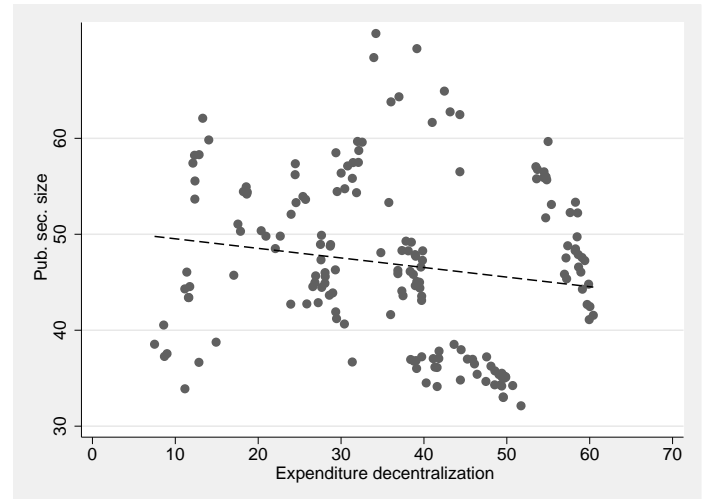

(b) Right-wing administrations

Figure 2: Impact of expenditure decentralization on public sector size under left- and rightwing administrations, OECD countries, 1980-2000

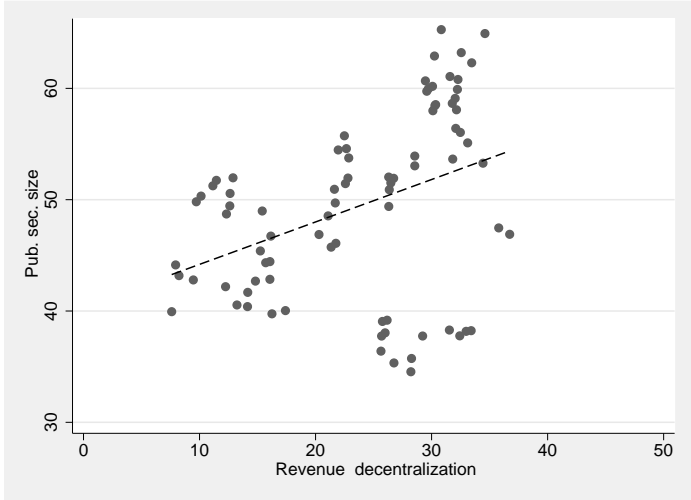

(a) Left-wing administrations

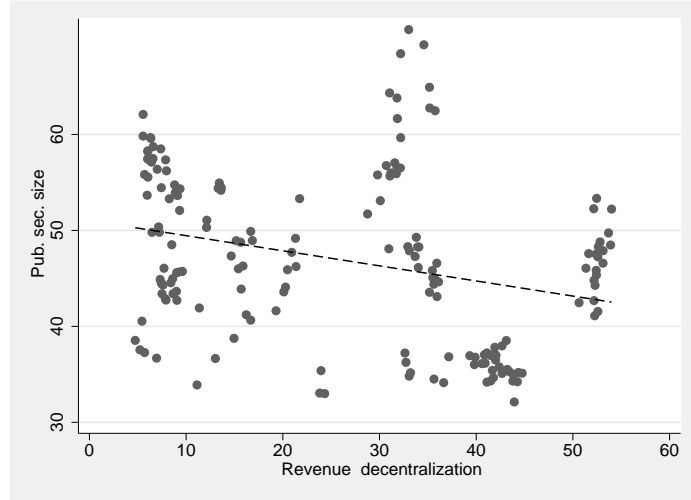

(b) Right-wing administration

Figure 3: Impact of revenue decentralization on public sector size under left- and right-wing administrations, OECD countries, 1980-2000 
Table 1: Definition and Source of Variables

\begin{tabular}{|c|c|c|}
\hline Label & Description & Source \\
\hline & Dependent variable & \\
\hline \multirow[t]{2}{*}{ Public sector size } & $\begin{array}{l}\text { Logistic transformation of public ex- } \\
\text { penditures/GDP }\end{array}$ & OECD Economic Outlook No. 83 \\
\hline & Decentralization variables & \\
\hline Exp. decentralization & $\begin{array}{l}\text { Subnational share of total government } \\
\text { expenditures }\end{array}$ & $\begin{array}{l}\text { The World Bank's Country Database } \\
\text { on Fiscal Decentralization (based on } \\
\text { the IMF's GFS data) }\end{array}$ \\
\hline Rev. decentralization & $\begin{array}{l}\text { Subnational share of total government } \\
\text { revenues }\end{array}$ & $\begin{array}{l}\text { The World Bank's Country Database } \\
\text { on Fiscal Decentralization (based on } \\
\text { the IMF's GFS data) }\end{array}$ \\
\hline \multirow[b]{2}{*}{ Ideology } & Ideological variable & \\
\hline & $\begin{array}{l}\text { Index of the ideology of government, } \\
\text { higher values indicate more leftist ide- } \\
\text { ology }\end{array}$ & $\begin{array}{l}\text { CPDS I Dataset } \\
\text { (Armingeon et al., 2008) }\end{array}$ \\
\hline \multicolumn{3}{|c|}{ Interactions } \\
\hline Exp. dec. $\times$ Ideology & $\begin{array}{l}\text { Interaction between ideology-index } \\
\text { and expenditure decentralization }\end{array}$ & $\begin{array}{l}\text { Own calculations based on original } \\
\text { data }\end{array}$ \\
\hline Rev. dec. $\times$ Ideology & $\begin{array}{l}\text { Interaction between ideology-index } \\
\text { and revenue decentralization }\end{array}$ & $\begin{array}{l}\text { Own calculations based on original } \\
\text { data }\end{array}$ \\
\hline \multicolumn{3}{|c|}{ Control variables } \\
\hline Population & Logarithm of Population & $\begin{array}{l}\text { OECD Population and Labour Force } \\
\text { Statistics }\end{array}$ \\
\hline Working & $\begin{array}{l}\text { Share of population between } 15-65 \\
\text { years }\end{array}$ & $\begin{array}{l}\text { OECD Population and Labour Force } \\
\text { Statistics }\end{array}$ \\
\hline Pop. density & Population density & UN (World Population Prospects) \\
\hline GDP p. c. & GDP per capita & OECD Annual National Accounts \\
\hline Unemployment & Unemployment rate & OECD Economic Outlook No. 83 \\
\hline Openness & $\begin{array}{l}\text { Trade openness } \\
\text { ports+imports]/GDP) }\end{array}$ & OECD Macro Trade Indicators \\
\hline Herf. index & $\begin{array}{l}\text { Herfindahl index of government con- } \\
\text { centration, higher values indicate less } \\
\text { fragmented governments }\end{array}$ & DPI 2006 Dataset (Beck et al., 2001) \\
\hline \multirow{3}{*}{ Urbanity } & Excluded instrument & \\
\hline & $\begin{array}{l}\text { Share of Population living in urban ar- } \\
\text { eas }\end{array}$ & UN (World Population Prospects) \\
\hline & Constructed instruments & \\
\hline Prediction of Exp. Dec $\times$ Ideology & $\begin{array}{l}\text { Non-linear function (of a linear com- } \\
\text { bination) of in- and excluded instru- } \\
\text { ments }\end{array}$ & $\begin{array}{l}\text { Own construction after Wooldridge } \\
(2002) \text {, see main text for explanation }\end{array}$ \\
\hline Prediction of Rev. Dec. $\times$ Ideology & $\begin{array}{l}\text { Non-linear function (of a linear com- } \\
\text { bination) of in- and excluded instru- } \\
\text { ments }\end{array}$ & $\begin{array}{l}\text { Own construction after Wooldridge } \\
(2002) \text {, see main text for explanation }\end{array}$ \\
\hline
\end{tabular}


In order to investigate whether the findings from the bivariate plots are robust to a more elaborate methodology, we estimate the following general model in various individual specifications

Pub. sec. size $=a_{i}+\gamma_{t}+b_{1}$ Decentralization $+b_{2}$ Ideology $+b_{3}$ Decentralization $\times$ Ideology $+\mathbf{b}$ Control variables $+\epsilon$.

In this equation, the $a$ and $\gamma$ coefficients are cross-section and time-fixed effects, $\epsilon$ is the error-term. The remaining variables and their sources are listed in table 1.

The dependent variable is the size of the public sector (Pub. sec. size). It is measured by the ratio of total government expenditures to GDP. We follow Oates (1985) and Marlow (1988) by applying a logistic transformation to this measure in the regressions. The reason for this transformation is that the expenditure to GDP ratio is constrained to lie between 0 and 1, thus contradicting the assumptions for Least Squares to be appropriate.

In order to test Hypothesis $A$, we construct two interaction variables by multiplying the ideology with the decentralization variables. They are denominated as Exp. dec. $\times$ Ideology and Rev. dec. $\times$ Ideology in the regression tables. Interaction variables are routinely used to explore conditional hypotheses. The conditional hypothesis in the current context is that decentralization leads to a larger public sector size when the central government is left-wing and to a smaller public sector size when it is right-wing.

There are, however, some pitfalls in estimating interaction models, both regarding specification and interpretation (Brambor et al., 2006). Regarding specification, Brambor et al. (2006) show that all constituent terms of an interaction variable have to be included in the model in order to avoid an omitted variable bias. This implies for the current case that not only Exp. dec. $\times$ Ideology and Rev. dec. $\times$ Ideology must be included in model 28, but also each of the constituent variables separately, i. e. Exp. dec., Rev. dec. and Ideology.

Regarding interpretation, it follows from Brambor et al. (2006) that the marginal effect of decentralization on public sector size is

$$
\frac{d \text { Pub. sec. size }}{d \text { Decentralization }}=b_{1}+b_{3} \text { Ideology } .
$$

That is, the marginal effect of an additional increase of decentralization depends on the value of the ideology variable.

The theoretical model predicts that $b_{1}+b_{3}$ Ideology is negative if Ideology $=1$, i. e. when the central government is far right, and that it is positive if Ideology=5, i. e. when the central government is far left. Therefore, we provide the marginal effect and the corresponding tstatistics for the decentralization variable when Ideology $=1$ and Ideology $=5$ in the regression tables further below.

A fortiori, the theory also predicts that $b_{1}+b_{3}$ Ideology $=5>b_{1}+b_{3}$ Ideology=1, i. e. that the marginal effect of decentralization on public sector size is "more positive" under a leftand a right-wing government. Therefore, we also provide in the regression tables the p-values from a z-test of this hypothesis. (This test is discussed in more detail further below.)

We include a number of additional control variables which might influence the size of the public sector. We consider the (log of) population size (Population), the share of the nondependent population (Working), the population density (Pop. density), GDP per capita 
(GDP p. c.), the unemployment rate (Unemployment), the trade openness of the economy (Openness), and the Herfindahl index of government fragmentation (Herf. index).

All control variables and their sources are listed in table 1. A cross-correlation matrix is provided in table C.1 in Appendix C. ${ }^{21}$ Summary statistics are provided in table C.2 in the same Appendix.

Since the Hausman test consistently indicates that country fixed effects belong in model 28, we only report the results from fixed effects regressions. Fixed effects models implicitly take account of (largely) time-constant country specific features that are difficult to measure explicitly, for example moral hazard problems due to the presence of intergovernmental transfer schemes (Goodspeed, 2002). However, the use of fixed effects precludes the explicit inclusion of variables which capture the largely time-constant institutional structure of a country, i.e. whether a country is a presidential or parliamentary democracy, or whether it is federal or unitary.

\subsection{Results}

\subsubsection{Baseline results}

We start with reporting our baseline results in table 2. These are derived from simple fixed effects regressions with both the expenditure and revenue decentralization measures. The first specification in both sets of models only includes a linear control for decentralization (ED (I) and RD (I)). A variant of this model is traditionally used to explore the Leviathan Hypothesis. We append this basic model consecutively in subsequent specifications. In the second specification, we include the interaction variable in order to test the hypothesis that decentralization under a left-wing administration increases and under a right-wing government decreases public sector size (ED (II) and RD (II)). In the third specification (ED (III) and RD (III)), we additionally include year-fixed effects in order to control for contemporaneous correlation between countries. In the fourth specification (ED (IV) and RD (IV)), we take autocorrelation within countries into account by conducting the hypothesis tests on the basis of clustered standard errors. Note that hypothesis tests in all models are conducted with robust standard errors in order to take potential heteroscedasticity into account.

We first discuss briefly the estimation results for the control variables before we focus the effect of decentralization and ideology. The results for the control variables in table 2 are generally similar between the regressions with expenditure and revenue decentralization.

We find that an increase in population size significantly increases the size of the public sector. An explanation for this result is that the population increases within countries either because of an increase in the birth rate, a decrease in old age mortality, or through more immigration. It is a reasonable conjecture that all three explanations for population growth might lead to a short-term expansion of government activity.

\footnotetext{
${ }^{21}$ This cross-correlation matrix is constructed with the variables in levels. In addition, we have also constructed a cross-correlation matrix with cross-section and time-demeaned values (not reported but available upon request). Neither of these two matrices suggest major multicollinearity problems. Population density and GDP per capita appear to be the only variables that display somewhat noteworthy correlations with the decentralization variables. However, running the IV regressions further below after excluding these variables one at a time does not change the main conclusions. We have also experimented with a principal components analysis in order to address potential multicollinearity problems. We derived the principal components of all control variables except the decentralization and ideology variables and included them successively in a regression model similar to model 28. We found that when enough components are included, the results are similar to those reported further below.
} 
The share of the non-dependent population is negatively related to the size of the public sector. This result is reasonable since a less dependent population decreases spending needs.

Population density is negatively related to the size of the public sector. This result suggests that scale economies exist in the provision of public goods.

GDP per capita is negatively related to the size of the public sector. This result is expected and can be explained, for example, by the argument that more prosperous societies depend less on interpersonal risk sharing through social security transfers when private resources are sufficient to absorb negative economic shocks. However, the finding could also be statistical artifact produced by the presence of GDP in the denominator of the dependent variable and in the nominator of the GDP $p . c$. variable in equation 28. While we are not particularly interested in the effect of GDP per capita on public sector size in this paper, this "ratio problem" could lead to biased estimates of our variables of interest. ${ }^{22}$ However, we have investigated this possibility in two robustness checks and found that the conclusions with regard to the variables of interest remain valid (these robustness checks are not reported, but available from the author). ${ }^{23}$

The unemployment rate is positively related to public sector size, presumably because a high level of unemployment leads to increased expenditures for social protection and countercyclical fiscal policies.

The coefficient on the openness variable is significantly negative. More open countries seem to have smaller governments than closed economies, thus indicating that a higher exposure to international competition limits government intervention.

The coefficient on the Herfindahl index is insignificant, suggesting that government fragmentation has no significant effect on public sector size.

The political and decentralization variables are our main concern. In particular, the interaction between expenditure decentralization and the ideology variable is used to explore the implications of the theoretical model. When no interaction variables are used (ED (I) and RD (I)), the coefficient on the decentralization variable is significantly positive. At face value, this result suggests that more decentralized states have larger governments, in turn indicating that the simple linear Leviathan Hypothesis- that decentralization decreases public sector size- is not correct.

The inclusion of the interaction variable does not lead to a re-evaluation of this particular conclusion. The marginal effect of the decentralization variables when the central government is right-wing and when it is left-wing, reported at the bottom of the table in the rows labeled with Dec. $\times$ Left and Dec. $\times$ Right, is always positive and exhibits large t-statistics. Hence, the Leviathan Hypothesis is rejected by these regressions even when the ideology of the central government is taken into account. Consequently, we also find no support for Hypothesis $A$ in its basic formulation.

However, note that the numerical value of the marginal effect is always larger for a leftthan a right-wing government. This suggest that while decentralization always increases

\footnotetext{
${ }^{22}$ See Kronmal (1993) for a more detailed discussion.

${ }^{23}$ We applied two different strategies to explore whether our results are sensitive to the "ratio problem". First, we simply estimated equation 28 without including GDP per capita in the set of explanatory variables. Second, we estimated models where we do not scale expenditures by GDP but instead specify as dependent variable the log of total (nominal) expenditures, and include as additional independent variables the GDP deflator (to take account of the fact that expenditures are given in nominal terms) and the level of GDP. In both cases, we used the instrumental variables approach.
} 
public sector size, it leads to a larger increase under a left than a right-wing government. This hypothesis is tested formally with a (one-sided) z-test. The $H_{0}$ is that the marginal effect of decentralization is larger under a left- than a right-wing government. The p-values for these tests are also reported at the bottom of table 2 . We find that $H_{0}$ can never be rejected at conventional significance levels.

One drawback of this test is that a particular formulation of $H_{0}$ and the corresponding $H_{1}$ has significant implications for the conclusions. That is, if $H_{0}$ were that the marginal effect of decentralization under a right-wing government has a larger effect than under a left-wing government, the conclusions would differ. Therefore, the test should also be conducted with a alternative $H_{0}$ stating that the effect is larger for right-wing than for left-wing governments. If this alternative $H_{0}$ is rejected (given that the original $H_{0}$ is not rejected), we can be reasonably sure that the marginal effect is larger for left- than for right-wing governments. Fortunately, no separate p-values for this alternative hypothesis need to be reported because the appropriate p-value is just one minus the p-value for the original $H_{0}$. Therefore, it is immediately clear from table 2 that the hypothesis stating that the marginal effect of decentralization is larger under a right-wing government can be rejected at conventional significance levels for expenditure decentralization. For revenue decentralization, however, the p-values would always be over $10 \%$ (since the p-values for the original hypothesis are always below $90 \%)$.

Even though the evidence is relatively weak for the revenue decentralization regressions, we find that these results, overall, suggest that the "public-sector size increasing" effect of decentralization is significantly larger under a left- than a right-wing government. Presumably, the "non-ideology" effects of decentralization, such as common pool problems and soft budget constraints $^{24}$, lead to such large increases in the public sector size that ideological differences have no impact on the direction of the aggregate effect. However, ideological differences affect the magnitude of the effect in a way that is consistent with our theory. Thus, we find some evidence for a reformulated version of Hypothesis $A$.

In the following, we will explore whether this result remains valid in a number of robustness checks.

\footnotetext{
${ }^{24}$ For example, Sorribas-Navarro (2010) provides empirical evidence for soft budget constraints in Spain during the 1986-2006 period, i. e. around a time when Spain had initiated significant fiscal decentralization.
} 
Table 2: Impact of expenditure and Revenue decentralization on public SeCtor size, 1980-2000, Fixed EFFECTS MODELS

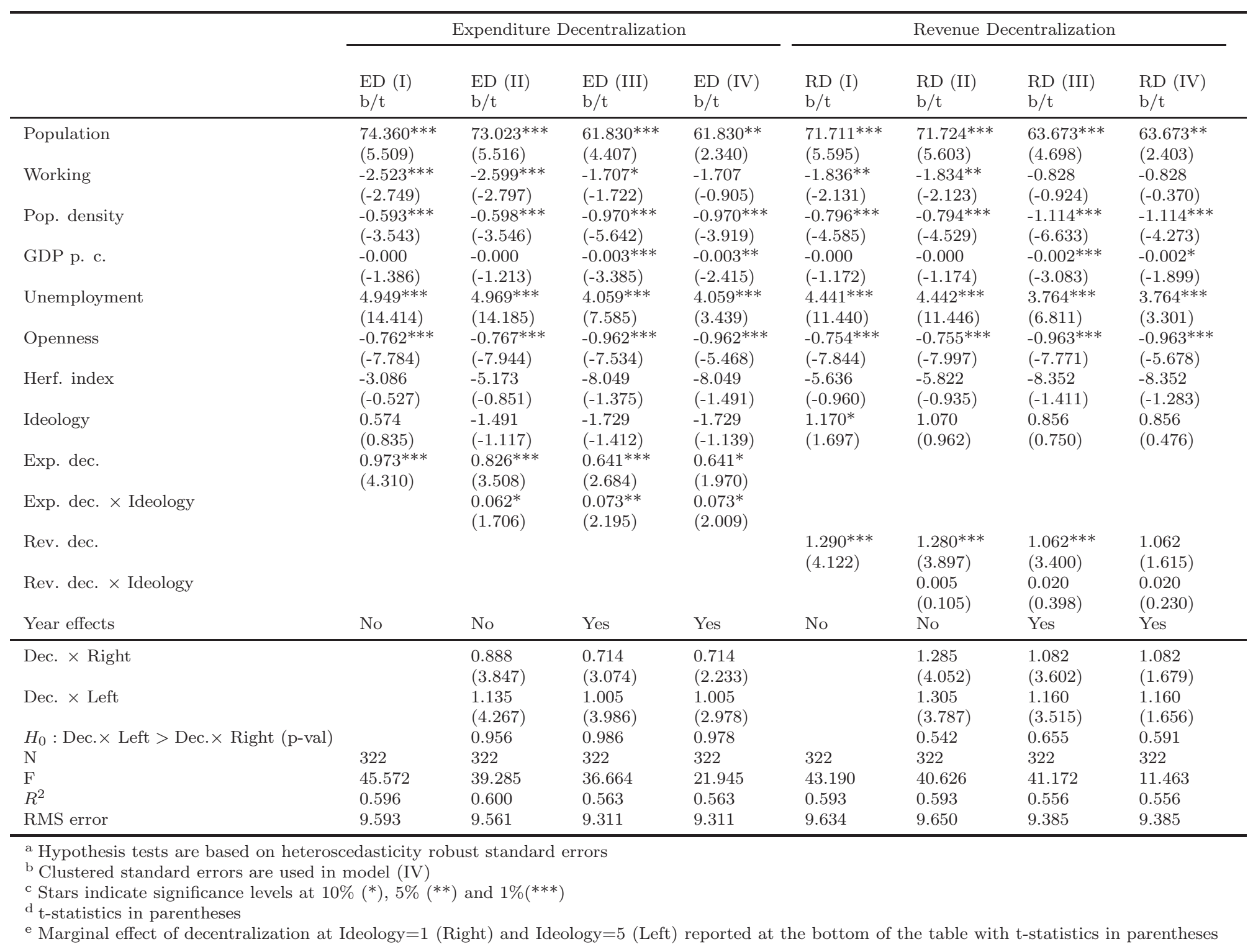




\subsubsection{Robustness checks with IV regressions}

Since both the expenditure and the revenue decentralization variables are constructed with fiscal variables, it is conceivable that both are simultaneously determined with the size of the public sector since the latter is also a fiscal variable. Hence, the previous results might be biased because both the expenditure and revenue decentralization variables, and their interactions with the Ideology variable might be endogenous. We therefore re-evaluate the results from the previous section with an instrumental variable approach.

First, we use as excluded instruments for the decentralization variables and their interactions with the Ideology variable an urbanity index. Second, we use two additional instrumental variables which are constructed according to a procedure proposed in Wooldridge (2002).

In this procedure, the endogenous decentralization variables are linearly projected into the space spanned by the (in- and excluded) ${ }^{25}$ instruments. ${ }^{26}$ The linear projections are then interacted with the Ideology variable, which results in a non-linear transformation of the linear prediction. These non-linear transformations can then be used as additional instruments since they are solely based on exogenous variables. ${ }^{27}$ By applying this procedure, we obtain for each model altogether three excluded instruments for two potentially endogenous regressors (i. e. the decentralization variables and their interactions with the Ideology variable). Since we have therefore at least on overidentifying restriction for each model, we can calculate diagnostic statistics to confirm the validity of the set of instruments.

The results from the instrumental variable regressions are collected in table 3. Note that the instruments perform well. The over-identification test (Hansen J) generally suggests that they are valid. The relevance test generally indicates that the instruments are relevant.

The marginal effects reported at the bottom of the table suggest, as in the baseline models, that decentralization increases the size of the public sector irrespective of whether the central government is ruled by a left- or a right-wing government. As in the baseline model, the marginal effect is larger under a left- than a right-wing government. The findings in the IV regressions are therefore consistent with the baseline results. While the numerical values of the estimated coefficients are difficult to interpret due to the logistic transformation of the dependent variable, it is noteworthy that the absolute magnitude of the marginal effects is larger than in the baseline regressions.

\footnotetext{
${ }^{25}$ Note on terminology: "excluded" instruments are those variables that are not used as exogenous regressors in the second stage regressions, "included" instruments are those variables that are used as control variables in the second stage regression. See for example Baltagi (1998) for further details.

${ }^{26}$ Which also include the cross-section and time fixed effects.

${ }^{27}$ See Wooldridge (2002) for further details.
} 
Table 3: Impact of expenditure and Revenue decentralization on public SeCtor size, 1980-2000, Fixed EFFECTS MODELS WITH INSTRUMENTAL VARIABLES

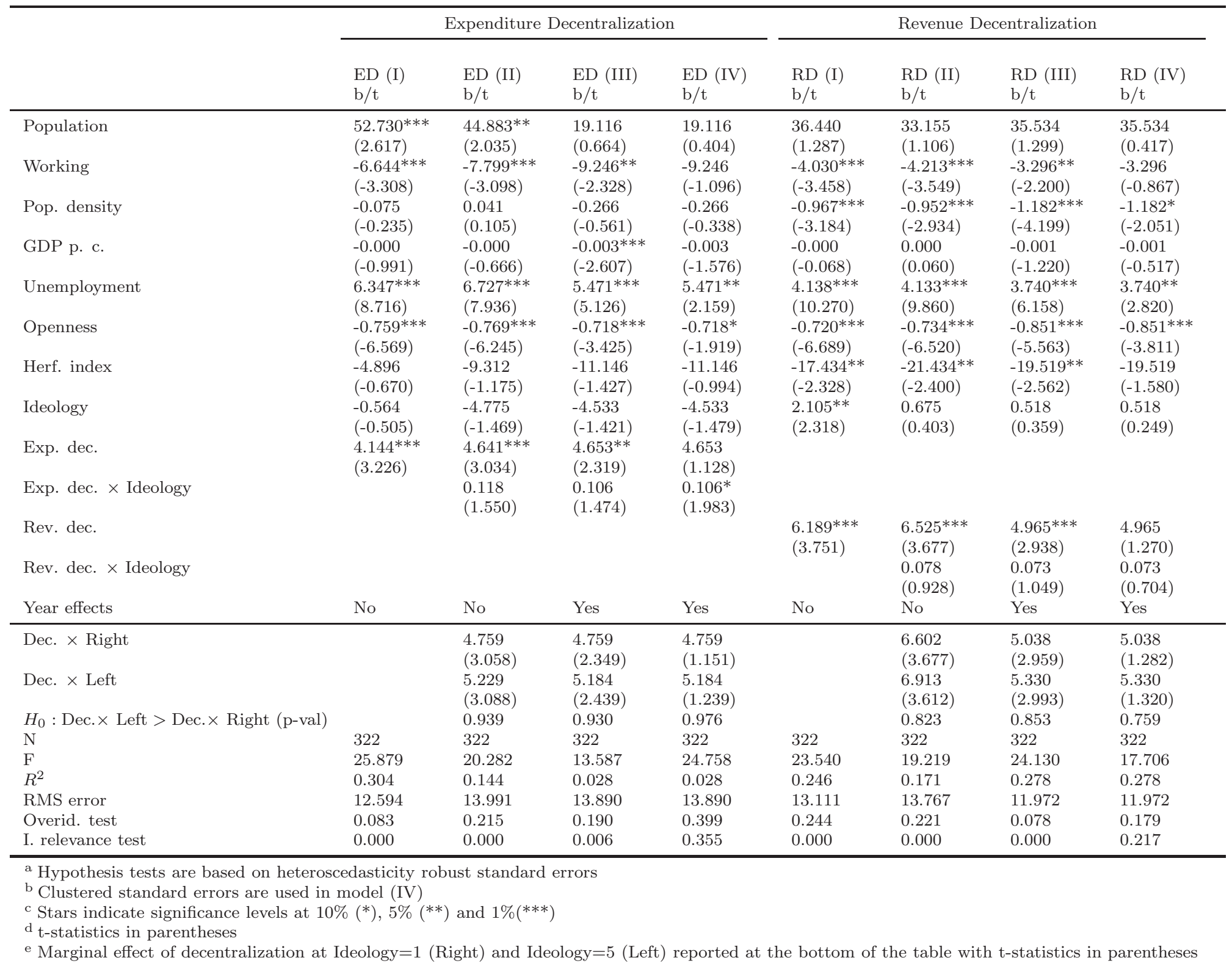




\subsubsection{Robustness checks with additional countries}

The previous regressions were confined to OECD countries. While this has the advantage that detailed ideology data is available and the institutional structure of all included countries is reasonably similar, it has the disadvantage of a relatively small sample size.

Therefore, this section presents the results of an estimation of model 28 with a larger set of countries. However, note that while we use variables that measure similar "concepts" as in the previous sections, we need to use different sources.

Most importantly, the CPDS I ideology measures are not available for non-OECD countries. In the regressions reported below, we therefore use the gov1rlc variable from the Database of Political Institutions (Beck et al., 2001). This variable measures the ideology of the largest government party on a three-digit scale. It codes right-wing parties as 1 , centrist parties as 2 , and left-wing parties as 3. (Parties that cannot be classified according to a left-right scale are coded as 0 . These observations are dropped by us.) Note that this variable is less precise then the CPDS I measures since it only uses a three-digit scale. Moreover, it is probably also narrower since it captures only the ideology of one, albeit the largest, government party. The results from these regressions should therefore be interpreted with caution.

We continue to use the World Bank data to measure expenditure and revenue decentralization. With regard to the other control variables, we use the following sources. Government size is measured with the "government share" variable from the Penn World Tables. As in the last section, we use the logistic transformation as dependent variable. The population size and openness variables are also retrieved from the Penn World Tables. Population size is included in logs in the regressions. As an analogue for the share of the working population, we include the age-dependency ratio, i. e. the share of the old relative to the working population, which is retrieved from the World Bank's EdStats database. Population density and the unemployment rate are retrieved from the World Development Indicators. The HerfindahlIndex is from the Database of Political institutions and is the same already included in the baseline regressions.

Since we report IV regressions, an urbanity variable has to be retrieved for this larger set of countries. We use the measure from the the Vanhanen Index of Power Resources database (Vanhanen, 2003), which we retrieved from the Quality of Government database (Teorell et al., 2010). This data is only available until 1999, so that our sample period in these regressions is slightly smaller than in the previous sections.

Note that the World Development Indicators exhibit some missing observations for the Population density and the unemployment rate variables. Whenever observations are missing for these variables, we replace them, when available, with the values of the corresponding variables used in the baseline regressions. The correlation between the respective variables is high (in both cases over 0.95), so that this probably does not lead to distortions in the regressions.

As argued previously, decentralization is difficult to compare between democratic and autocratic states. In the regressions, we therefore use only observations for which the institutionalized democracy score $(D E M O C)$ from the Polity IV Project is larger than 5 (Marshall and Jaggers, 2002). (Higher values in this score imply higher levels of democracy with 10 being maximum democracy and 0 the minimum). This variable is also retrieved from the Quality of Government database (Teorell et al., 2010). 
We also drop all states with a population with less than 500,000 inhabitants since they are too small to be meaningfully decentralized, and countries with singleton observations in the dataset since we estimate fixed effects models.

After constructing the database in this way, the number of available countries is $44 .{ }^{28}$ The results from the regressions with this sample are reported in table 4. As in the previous regression tables, we report at the bottom this table the marginal effect of decentralization in case of a right $\left(b_{1}+b_{3}\right.$ Ideology $\left.=1\right)$ and a left-wing $\left(b_{1}+b_{3}\right.$ Ideology $\left.=3\right)$ government, and the p-value of a z-test on the hypothesis $b_{1}+b_{3}$ Ideology $=3>b_{1}+b_{3}$ Ideology $=1$.

We find that the results with respect to the variables of interest, the decentralization and ideology variables, are similar to the baseline regressions. First, the marginal effect of the decentralization variable is consistently positive. However, the significance levels are smaller. Second, the magnitude of the marginal effect is, with one exception, consistently larger for left- than for right-wing governments. Related to this, the hypothesis that the effect is larger for left-wing then right-wing government is never rejected at conventional significance levels. The opposite hypothesis is either rejected at conventional significance levels or displays small p-values for revenue decentralization (recall that the p-value of the hypothesis that the effect is larger for right-wing governments is just one minus the p-value of the original hypothesis). For expenditure decentralization, the p-values are larger. It is interesting to note that in these regressions, the results with respect to the variables of interest are stronger for revenue than expenditure decentralization.

\footnotetext{
${ }^{28}$ Argentina, Australia, Austria, Belgium, Bolivia, Brazil, Bulgaria, Canada, Chile, Colombia, Costa Rica, Czech Republic, Denmark, Dominican Republic, Estonia, Finland, France, Georgia, Germany, Hungary, Ireland, Israel, Italy, Latvia, Lithuania, Mexico, Netherlands, Norway, Panama, Paraguay, Peru, Poland, Portugal, Romania, Slovak Republic, Slovenia, South Africa, Spain, Sweden, Switzerland, Thailand, Trinidad and Tobago, United Kingdom, United States.
} 
Table 4: Impact of expenditure and Revenue decentralization on public sector size, 1980-1999, Fixed Effects models With Instrumental VARIABLES, OECD AND NON-OECD COUNTRIES (44 COUNTRIES)

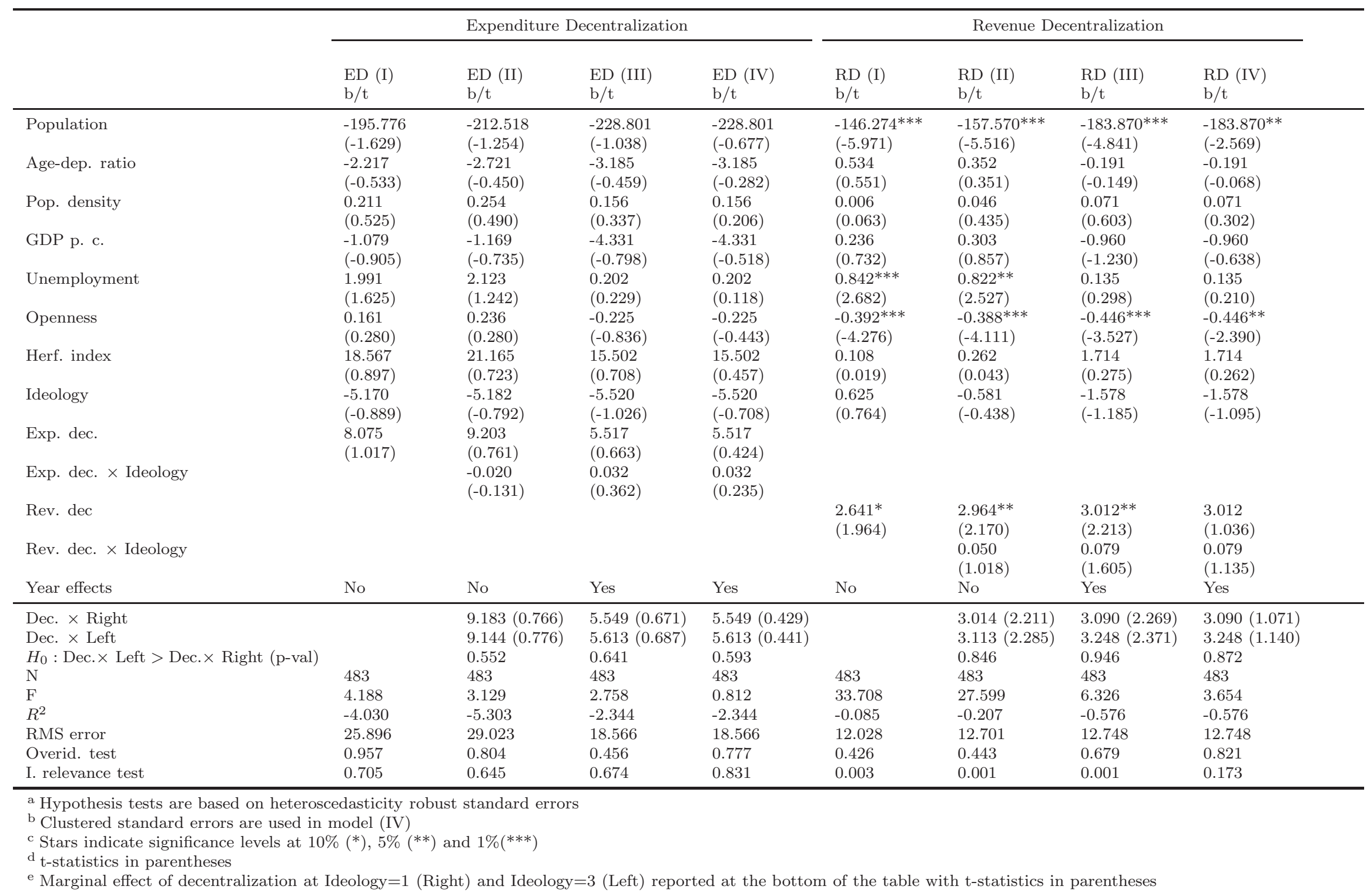




\section{Conclusion}

This paper is concerned with the relationship between fiscal decentralization and the size of the public sector. We first provide a short overview of the state of the literature. Recognizing that the theoretical link between fiscal decentralization and public sector expansion has not yet been fully explored, we develop a model that relates decentralization and the political affiliation of voters to the size of the public sector. The model results in the empirical hypothesis that fiscal decentralization leads to larger public sectors when the federal government is controlled by a left-wing party, and to smaller public sectors when it is controlled by a right-wing party.

We test this hypothesis in the empirical part of the paper. Our results suggest, in contrast to the theoretical hypothesis, that decentralization leads to an increase in the size of government irrespective of the ideology of the central government. However, we also find that the magnitude of the marginal effect is larger under a left- than under a right-wing government. Apparently, the non-ideological effects of decentralization, such as common pool problems, determine the overall direction of the impact of decentralization on public sector size. While the ideological effects are not strong enough to affect the overall direction, they influence its magnitude in a way that is consistent with the theoretical predictions. We therefore find some evidence for a adapted version of our original hypothesis.

That the empirical results are only partially consistent with the theoretical model may be due to the fact that there are some shortcomings in the latter. In particular, we make relatively strong assumptions about the fiscal constitution. For example, we assume that the federation operates under an efficient fiscal constitution. One avenue for future work is therefore to generalize the model by endogenizing the formulation of the fiscal constitution. Alternatively, more elaborate utility functions could be considered in order to study, for example, whether complementarity in the consumption of the private and public goods changes the results. Also, equalization schemes and intergovernmental grants could be incorporated. Such extensions may result in a model that is fully consistent with the empirical results.

In conclusion, we find that the ideology of the federal government matters for the effect of fiscal decentralization on public sector size. Nonetheless, we should be careful in reaching normative conclusions on the basis of these results. The Leviathan Hypothesis is based on a controversial view of government. The underlying assumption is that government intervention is "bad" and that small government is therefore always desirable. However, in our framework both "too large" and "too small" public sector sizes should be avoided. That decentralization leads to a smaller increase in the size of the public sector under a right- than under left-wing government does not imply that either right- or left-wing governments are "better". It only implies that they are different.

\section{Acknowledgments}

The author thanks an anonymous referee, Lars P. Feld, Zohal Hessami, and the participants of the American and European Public Choice meetings in Las Vegas and Athens for helpful comments and suggestions. Of course, the author alone is responsible for all remaining errors. Funding by the German Science Foundation (DFG-SPP 1142) is gratefully acknowledged. 


\section{Appendix A}

\section{Derivation of equation 12 and 13:}

Expanding the sum in equation 11 gives

$$
U^{s}=\int_{0}^{1} a_{r}(j)\left(c_{r}(j)+v(g(j))+W(G)\right) d j+\int_{0}^{1} a_{l}(j)\left(c_{l}(j)+v(g(j))+W(G)\right) d j
$$

It follows from the budget constraints of the federal and regional governments, i. e. equation 9 and 10 , that

$$
\begin{gathered}
t_{K}=\frac{G}{\int_{0}^{1} a_{r}(j) d j}, \text { and } \\
t_{l}(j)=\frac{g(j)}{a_{l}(j)} .
\end{gathered}
$$

Using these expression, we can write the individual budget constraints of the right- and left-wing supporters as

$$
\begin{gathered}
c_{r}(j)=\rho=\left(r-\frac{G}{\int_{0}^{1} a_{r}(j) d j}\right), \text { and } \\
c_{l}(j)=\omega(j)=w(j)-\frac{g(j)}{a_{l}(j)} .
\end{gathered}
$$

By substituting the right-hand side expressions for $c_{r}(j)$ and $c_{l}(j)$ into equation A.1, we obtain

$$
\begin{aligned}
U^{s}=\int_{0}^{1} a_{r}(j) & \left(r-\frac{G}{\int_{0}^{1} a_{r}(j) d j}+v(g(j))+W(G)\right) d j \\
& +\int_{0}^{1} a_{l}(j)\left(w(j)-\frac{g(j)}{a_{l}(j)}+v(g(j))+W(G)\right) d j .
\end{aligned}
$$

Differentiating expression A.6 with respect to $g(j)$ gives $^{29}$

$$
a_{r}(j) \frac{d v}{d g_{j}}+a_{l}(j)\left(-\frac{1}{a_{l}(j)}+\frac{d v}{d g_{j}}\right)=0
$$

Since $a_{r}(j)+a_{l}(j)=1$ in every jurisdiction $j$, this expression simplifies to equation 12 .

Similarly, differentiating expression A.6 with respect to $G$ gives $^{30}$

$$
\int_{0}^{1} a_{r}(j)\left(-\frac{1}{\int_{0}^{1} a_{r}(j) d j}+\frac{d W}{d G}\right) d j+\int_{0}^{1} a_{l}(j) \frac{d W}{d G} d j=0
$$

\footnotetext{
${ }^{29}$ Note that $g(j)$ has a $j$ index, hence an individual first order condition has to be derived for every jurisdiction; however, since jurisdictions are assumed to be identical, the first order condition further below is the same for all jurisdictions.

${ }^{30}$ Note that $G$ has no $j$ index, hence the first order condition pertains to the whole federation
} 
this simplifies to

$$
-1+\frac{d W}{d G} \int_{0}^{1}\left(a_{r}(j)+a_{l}(j)\right) d j=0 .
$$

Since $a_{r}(j)+a_{l}(j)=1$ in every jurisdiction, equation 13 follows.

\section{Derivation of equation 17 and 18}

Equation 17 can be obtained by substituting the right-hand side of expressions A.4 and A.5 for $c_{l}(j)$ and $c_{r}(j)$ into equation 16. It follows after expanding the sum

$U^{s}(j)=a_{r}(j)\left(r-\frac{G}{\int_{0}^{1} a_{r}(j) d j}+v(g(j))+W(G)\right)+a_{l}(j)\left(w(j)-\frac{g(j)}{a_{l}(j)}+v(g(j))+W(G)\right)$.

Differentiating this expression with respect to $g(j)$, the choice variable of the subnational governments under decentralization, gives

$$
a_{r}(j) \frac{d v}{d g(j)}+a_{l}(j)\left(-\frac{1}{a_{l}(j)}+\frac{d v}{d g(j)}\right)=0 .
$$

Since $a_{r}(j)+a_{l}(j)=1$, this expression simplifies to equation 17 .

Similarly, after substituting for $c_{r}(j)$ and $c_{l}(j)$ and expanding the sum, the objective function of the central government can be written as:

$$
\begin{aligned}
U^{s}=\int_{0}^{1} a_{r}(j) & \left(r-\frac{G}{\int_{0}^{1} a_{r}(j) d j}+v(g(j))+W(G)\right) d j \\
& +\int_{0}^{1} a_{l}(j)\left(w(j)-\frac{g(j)}{a_{l}(j)}+v(g(j))+W(G)\right) d j .
\end{aligned}
$$

Maximizing this objective function with respect to the choice variable of the federal government under decentralization, the level of the national public good $\mathrm{G}$, gives

$$
\int_{0}^{1} a_{r}(j)\left(-\frac{1}{\int_{0}^{1} a_{r}(j) d j}+\frac{d W}{d G}\right) d j+\int_{0}^{1} a_{l}(j) \frac{d W}{d G} d j=0
$$

which simplifies, as shown previously, to equation 18 .

The derivation of these two equations is obviously similar to the one for equation 12 and 13 . It differs only in that the optimizations are not conducted by a single benevolent government, but separately by a benevolent federal and a number of benevolent subnational governments. Given that we have assumed a fiscal constitution where inefficient fiscal interactions cannot emerge, the allocations in a centralized and a decentralized public sector are both efficient (and hence identical) if governments are benevolent. 


\section{Derivation of equation 20 and 22}

Equation 20 can be obtained by substituting the right hand side of expression A.5 into equation 19, the objective function of a left-wing government in jurisdiction $j$

$$
U_{l}(j)=a_{l}(j)\left(w(j)-\frac{g(j)}{a_{l}(j)}+\ln (g(j))+\ln (G)\right) .
$$

Differentiating this expression with respect to $g(j)$ gives

$$
-1+\frac{a_{l}(j)}{g(j)}=0
$$

which can be rearranged to expression 20 through division by $-a_{l}(j)$.

Equation 22 follows by substituting the right-hand side of expression A.4 for $c_{r}(j)$ in the objective function of a right-wing federal government given in equation 21

$$
U^{s}=\int_{0}^{1} a_{r}(j)\left(r-\frac{G}{\int_{0}^{1} a_{r}(j) d j}+v(g(j))+W(G)\right) d j .
$$

Differentiating this expression with respect to $G$ gives as first order condition

$$
-1+\frac{1}{G} \int_{0}^{1} a_{r}(j) d j=0 .
$$

By using the definition $R=\int_{0}^{1} a_{r}(j)$ and rearranging, expression 22 can be obtained.

\section{Appendix B}

We show in this appendix that the main theoretical result in this paper (Result $A$ ) continues to hold under less restrictive assumptions about the spending limits. We therefore relax the assumption that the highest possible level of the national and local public goods is the efficient level and assume instead that the limits are given by the general parameters $\bar{G}$ and $\bar{g}$, respectively.

Since a right-wing government under centralization will provide the level of the national public good that is preferred by its constituency, and the maximum amount of the local public good in each jurisdiction, the aggregate size of the public sector under a right-wing federal government is given by

$$
S_{r}^{c}=\bar{g}+R
$$

Equally, the size of the public sector under a left-wing government is given by

$$
S_{l}^{c}=\bar{G}+\int_{0}^{1} a_{l}(j) d j=\bar{G}+L .
$$

We see from these expressions that when the public sector is centralized, public sector size under different ideological governments depends on the relative magnitudes of the national and subnational spending limits. If $\bar{G}>\bar{g}$, left-wing governments will exhibit a larger public 
sector than right-wing administrations and vice versa. However, note that when $\bar{G}=\bar{g}$, the previous finding of no systematic differences between left- and right-wing governments in centralized public sectors will continue to remain valid.

Under decentralization and a right-wing federal government, the aggregate size of the public sector is given by

$$
S_{r}^{d}=1+R+(\bar{g}-1) j^{c r i t}-\int_{j^{c r i t}}^{1} a_{r}(j) d j .
$$

Under decentralization and a left-wing federal government, the aggregate public sector size is given by

$$
S_{l}^{d}=1+\bar{G}+(\bar{g}-1) j^{c r i t}-\int_{j^{c r i t}}^{1} a_{r}(j) d j .
$$

These expressions reveal that a left-wing federal government is always associated with a larger public sector than a right wing federal government under decentralization (since $\bar{G} \geq R$ by definition).

With these expressions, we can discuss the conditions under which the main theoretical result in this paper remains valid in this more general case. Remember that Result $A$ states that decentralization decreases the size of the public sector under a right-wing federal government whereas it increases it under a left-wing federal government. In view of this hypothesis, we derive the following proposition.

Proposition 1. i) Right-wing federal governments: centralization will lead to a larger public sector size than decentralization when

$$
\bar{g}>1-\frac{\int_{j^{c r i t}}^{1} a_{r}(j) d j}{1-j^{\text {crit }}}
$$

ii) Left-wing federal governments: decentralization will lead to a larger public sector size than centralization when

$$
\bar{g}>1+\frac{L-1+\int_{j}^{1}{ }_{j}{ }^{c i t} a_{r}(j) d j}{j^{c r i t}} .
$$

This proposition reveals that Result $A$ remains valid if the spending limit on the local public good is not set too low. In the case of a right-wing federal government, it can be easily seen that the minimum permissible spending limit at which the result continues to hold is always less than the efficient level, which is 1 . Similarly, the minimum permissible spending limit in the case of left-wing federal governments is also always less than 1 because the expression $L-1+\int_{j \text { crit }}^{1} a_{r}(j) d j$ is always negative. It seems reasonable to assume that in real-world countries, spending limits, if they exist, are always (weakly) larger than the efficient level. ${ }^{31}$

We thus conclude that our theoretical result is sufficiently robust to more general formulations with respect to the spending limits.

\footnotetext{
${ }^{31}$ If they were not, then jurisdictions that are completely populated by left-wing voters would not be allowed to choose their preferred level of the local public good. It seems not particularly realistic to assume that a rational constitutional assembly would choose such spending limits.
} 


\section{Appendix C}

Table C.1: Cross-Correlation table

\begin{tabular}{|c|c|c|c|c|c|c|c|c|c|c|c|}
\hline & Pub. sec. size & Population & Working & Pop. density & GDP p. c. & Unemp. & Openness & Herf. index & Ideology & Exp. dec. & Rev. dec. \\
\hline Pub. sec. size & 1.000 & & & & & & & & & & \\
\hline Population & -0.421 & 1.000 & & & & & & & & & \\
\hline Working & -0.092 & 0.240 & 1.000 & & & & & & & & \\
\hline Pop. density & 0.208 & 0.117 & 0.318 & 1.000 & & & & & & & \\
\hline GDP p. с. & -0.076 & 0.104 & 0.246 & -0.066 & 1.000 & & & & & & \\
\hline Unemp. & 0.016 & 0.135 & -0.149 & 0.030 & -0.474 & 1.000 & & & & & \\
\hline Openness & 0.444 & -0.611 & -0.140 & 0.497 & -0.064 & 0.058 & 1.000 & & & & \\
\hline Herf. index & -0.338 & 0.409 & -0.246 & -0.385 & -0.159 & 0.156 & -0.477 & 1.000 & & & \\
\hline Ideology & 0.149 & -0.265 & -0.116 & -0.172 & -0.004 & -0.085 & -0.012 & 0.157 & 1.000 & & \\
\hline Exp. dec. & -0.138 & -0.038 & 0.219 & -0.465 & 0.437 & -0.242 & -0.324 & 0.075 & -0.059 & 1.000 & \\
\hline Rev. dec. & -0.186 & 0.163 & 0.282 & -0.514 & 0.472 & -0.286 & -0.447 & 0.113 & -0.146 & 0.851 & 1.000 \\
\hline
\end{tabular}


Table C.2: Summary statistics of variables (sample average), By Countries

\begin{tabular}{llllllllllll}
\hline Country & $\begin{array}{l}\text { Pub. } \\
\text { size }\end{array}$ & sec. & $\begin{array}{l}\text { Popu- } \\
\text { lation }\end{array}$ & Working & $\begin{array}{l}\text { Pop. } \\
\text { density }\end{array}$ & $\begin{array}{l}\text { GDP p. } \\
\text { c. }\end{array}$ & $\begin{array}{l}\text { Unemp- } \\
\text { loyment }\end{array}$ & Openness $\begin{array}{l}\text { Herf. } \\
\text { index }\end{array}$ & $\begin{array}{l}\text { Ideology } \\
\text { Exp. } \\
\text { dec. }\end{array}$ & $\begin{array}{l}\text { Rev. } \\
\text { dec. }\end{array}$ \\
\hline AUS & 36.56 & 16854.80 & 66.37 & 2.11 & 21788.02 & 8.00 & 34.78 & 0.88 & 3.60 & 48.54 & 28.79 \\
AUT & 53.08 & 7775.30 & 67.02 & 92.13 & 23068.53 & 4.21 & 71.69 & 0.65 & 3.50 & 31.29 & 26.75 \\
BEL & 55.08 & 9979.47 & 66.59 & 324.50 & 21947.14 & 8.91 & 132.78 & 0.28 & 2.32 & 12.35 & 5.78 \\
CAN & 46.86 & 27606.90 & 68.05 & 2.71 & 23293.68 & 9.35 & 60.97 & 1.00 & 1.00 & 58.66 & 52.52 \\
CHE & 34.76 & 7024.71 & 67.76 & 170.20 & 29746.53 & 3.35 & 72.24 & 0.26 & 2.00 & 49.79 & 43.66 \\
DNK & 56.59 & 5181.91 & 66.74 & 119.74 & 23426.63 & 6.55 & 72.03 & 0.54 & 2.57 & 55.27 & 31.60 \\
ESP & 41.90 & 38694.89 & 65.88 & 76.00 & 15489.19 & 15.00 & 38.87 & 0.99 & 4.06 & 25.88 & 15.12 \\
FIN & 50.94 & 4975.21 & 67.43 & 14.60 & 19907.19 & 8.85 & 57.39 & 0.35 & 2.63 & 42.29 & 31.24 \\
FRA & 51.18 & 56203.71 & 65.38 & 101.15 & 20494.75 & 8.64 & 44.39 & 0.67 & 3.00 & 19.83 & 12.03 \\
GBR & 44.85 & 57187.00 & 65.02 & 234.53 & 19728.29 & 9.21 & 52.72 & 1.00 & 1.32 & 27.94 & 12.51 \\
GER & 46.50 & 69907.10 & 68.72 & 221.67 & 20945.98 & 7.15 & 48.41 & 0.55 & 1.47 & 39.07 & 34.72 \\
IRL & 48.04 & 3536.01 & 61.37 & 49.88 & 14929.96 & 14.24 & 115.07 & 0.74 & 1.89 & 27.22 & 8.16 \\
ITA & 50.23 & 56802.65 & 69.04 & 188.86 & 21893.83 & 10.54 & 42.23 & 0.71 & 2.67 & 23.37 & 8.92 \\
NLD & 55.48 & 14850.94 & 68.22 & 353.63 & 21911.97 & 7.30 & 110.93 & 0.51 & 2.06 & 30.25 & 7.81 \\
NOR & 49.37 & 4249.60 & 64.34 & 10.93 & 27404.58 & 3.79 & 73.25 & 0.74 & 3.40 & 37.13 & 21.50 \\
PRT & 42.15 & 9901.70 & 67.32 & 108.78 & 13636.24 & 5.84 & 64.11 & 1.00 & 1.83 & 10.84 & 7.14 \\
SWE & 62.74 & 8561.80 & 64.18 & 18.92 & 22526.84 & 4.36 & 65.64 & 0.73 & 3.85 & 38.68 & 32.05 \\
USA & 36.29 & 252249.00 & 65.96 & 26.14 & 27783.72 & 6.40 & 20.85 & 1.00 & 1.00 & 42.94 & 40.62 \\
\hline
\end{tabular}

${ }^{a}$ Summary statistics for the Pub. sec. size and Population variables are calculated for the levels and not the transformed variables for easier interpretability

Summary statistics are based on the observations included in the (baseline) regressions with OECD countries

${ }^{\mathrm{c}}$ For Germany before 1991, only data from the western part is used 


\section{References}

Armingeon, K., Gerber, M., Leimgruber, P., Beyeler, M., 2008. Comparative political data set 1960-2006. Institute of Political Science, University of Berne 2008 (Database).

Baltagi, B. H., 1998. Econometrics. Springer, New York.

Beck, T., Clarke, G., Groff, A., Keefer, P., Walsh, P., 2001. New tools in comparative political economy: the database of political institutions. World Bank Economic Review 15, 165-176.

Brambor, T., Clark, W. R., Golder, M., 2006. Understanding interaction models: improving empirical analyses. Political Analysis 14, 63-82.

Brennan, G., Buchanan, J., 1980. The power to tax: analytical foundations of a fiscal constitution. Cambridge University Press, Cambridge.

De Mello, L. R., 2000. Fiscal decentralization and intergovernmental fiscal relations: a cross country analysis. World Development 28, 365-380.

Feld, L. P., Schneider, F., 2000. State and local taxation. Mimeo (University of Linz).

Goodspeed, T. J., 2002. Bailouts in a federation. International Tax and Public Finance 9, 409-421.

Grossman, P. J., 1989. Fiscal decentralization and government size: an extension. Public Choice 62, 63-69.

Grossman, P. J., West, E. G., 1994. Federalism and the growth of government revisited. Public Choice 79, 19-32.

Hindriks, J., Lockwood, B., 2009. Decentralization and electoral accountability: incentives, separation and voter welfare. European Journal of Political Economy 25, 385-397.

Jin, J., Zou, H., 2002. How does fiscal decentralization affect aggregate, national, and subnational government size? Journal of Urban Economics 52, 270-293.

Keen, M. J., Kotsogiannis, C., 2002. Does federalism lead to excessively high taxes? American Economic Review 92, 363-370.

Kronmal, R. A., 1993. Spurious correlation and the fallacy of the ratio standard revisited. Journal of the Royal Statistical Society. Series A 156, 379-392.

Marlow, M. L., 1988. Fiscal decentralization and government size. Public Choice 56, 259-269.

Marshall, M. G., Jaggers, K., 2002. Polity IV project: political regime characteristics and transitions, 1800-2002, dataset users' manual. Mimeo (University of Maryland).

McKee, M. J., Visser, J. C., Saunders, P. G., 1986. Marginal tax rates on the use of labour and capital in OECD countries. In: OECD Economic Studies No. 7, Autumn 1986. OECD.

Neyapti, B., 2010. Fiscal decentralization and deficits: international evidence. European Journal of Political Economy 26, 155-166. 
Oates, W., 1985. Searching for Leviathan: an empirical study. American Economic Review $75,748-758$.

Rodden, J., 2003. Reviving Leviathan: fiscal federalism and the growth of government. International Organization 57, 695-729.

Schaltegger, C., Feld, L. P., 2009. Are fiscal adjustments less successful in decentralized governments? European Journal of Political Economy 25, 115-123.

Sengupta, B., 2010. Provision of public goods in a federal economy: the role of party politics. European Journal of Political Economy, doi: 10.1016/j.ejpoleco.2010.04.005.

Sorribas-Navarro, P., 2010. Bailouts in a fiscal federal system: evidence from Spain. European Journal of Political Economy, doi:10.1016/j.ejpoleco.2010.06.001.

Stegarescu, D., 2005. Public sector decentralization: measurement concepts and recent international trends. Fiscal Studies 26, 301-333.

Stein, E., 1998. Fiscal decentralization and government size in Latin America. In: Fukasaku, K., Hausmann, R. (Eds.), Democracy, Decentralization and Deficits in Latin America. IDB-OECD, Washington D.C., pp. 95-119.

Teorell, J., Samanni, M., Charron, N., Holmberg, S., Rothstein, B., 2010. The quality of government dataset, version 27May10. University of Gothenburg: The Quality of Government Institute, http://www.qog.pol.gu.se.

Vanhanen, T., 2003. Democratization and power resources 1850-2000. Tampere: Finnish Social Science Data Archive.

Weingast, B., Shepsle, K., Johnsen, C., 1981. The political economy of costs and benefits: a neoclassical approach to distributive politics. Journal of Political Economy 89, 642-664.

Wooldridge, J. M., 2002. Econometric analysis of cross section and panel data. MIT Press, Cambridge, MA.

Zodrow, G. R., Mieszkowski, P., 1986. Pigou, Tiebout, property taxation and the underprovision of local public goods. Journal of Urban Economics 19, 356-370. 